\title{
Intratumoral cancer chemotherapy with a carrier-based immunogenic cell death eliciting platinum (IV) agent
}

\author{
Chad Groer ${ }^{1}$, Ti Zhang ${ }^{1}$, Ruolin Lu $^{2}$, Shuang Cai ${ }^{1}$, Derek Mull ${ }^{1}$, Aric Huang ${ }^{2}$, Melanie \\ Forrest $^{1}$, Cory Berkland ${ }^{2,3}$, Daniel Aires ${ }^{1,4}$, Marcus Laird Forrest ${ }^{1,2,{ }^{*}}$ \\ ${ }^{1}$ HylaPharm LLC, Lawrence, Kansas \\ ${ }^{2}$ Department of Pharmaceutical Chemistry, University of Kansas, Lawrence, Kansas \\ ${ }^{3}$ Department of Chemical Engineering, University of Kansas, Lawrence, Kansas \\ ${ }^{4}$ Division of Dermatology, School of Medicine, The University of Kansas Medical Center, Kansas \\ City, Kansas
}

\section{Abstract}

A carrier-based, immunogenic cell death (ICD)-eliciting platinum(IV) chemotherapeutic agent was synthesized via complexation between an axially derivatized Pt(IV)-tocopherol and hyaluronan-tocopherol nanocarrier. The resultant HA-Pt(IV) complex demonstrated antiproliferative activity and induced calreticulin translocation, an indicator of ICD, in murine and human head and neck cancer cells. The intratumorally administered HA-Pt(IV) treatments were tolerable and efficacious in both immunocompetent and immunodeficient mice with head and neck cancer, partially due to the direct cytotoxicity. Superior efficacy and survival was observed in the immunocompetent group, suggesting a possible Pt(IV)-induced immunological response, which would only manifest in animals with an intact immune system. Subsequent imaging of tumor tissues demonstrated increased macrophage infiltration in the HA-Pt(IV) treated tumors compared to the non-treated controls and the cisplatin-treated tumors, suggesting favorable inflammatory activation. RNA sequencing of HA-Pt(IV)-treated tumors indicated that carbohydrate and vitamin metabolisms were the most important Kyoto Encyclopedia of Genes and Genomes (KEGG) pathway, and molecular function, biological process and cellular component were highly enriched gene ontology (GO) categories.

\section{Keywords}

Head and neck cancer; platinum (IV) chemotherapy; hyaluronic acid; immunogenic cell death; RNA sequencing; KEGG and GO analysis

\section{Introduction}

Head and neck cancers (HNCs) are the sixth most common cancer in people worldwide with over 630,000 new diagnoses each year and with an estimated incidence rate of 65,000 in the

\footnotetext{
*Corresponding Author: Dr. Marcus Laird Forrest, lforrest@ku.edu, Tel: 785-864-4388, Fax: 785-289-8131.
} 
United States alone ${ }^{1}$. HNCs are categorized based on the anatomical sites where they originate, such as the oral cavity (lips, tongue, gums, hard palate, floor of the mouth), nasal cavity and paranasal sinuses, salivary glands, pharynx (throat), and larynx (vocal cords) ${ }^{2}$. Treatment options include conventional modalities of surgery, radiation therapy and chemotherapy. Newer targeted therapies such as anti-epidermal growth factor receptor (EGFR) antibodies (e.g. Cetuximab) inhibit the stimulation of EGFRs in SCC, and checkpoint inhibitor immunotherapies disrupt the interactions between the programmed cell death protein 1 (PD1) and the programmed death ligand 1 (PDL1) (e.g. Pembrolizumab and Nivolumab) ${ }^{3}$. The selection of treatment modalities depends primarily on the location and the stage of the HNCs, in which concurrent and sequential uses of multiple modalities are common practices in the paradigm of HNC oncology.

In this report, the authors discuss the development and application of an intralesional (intratumoral) platinum(IV) chemotherapeutic for HNCs via direct tumor injection. The current work is based on previous preclinical and canine clinical studies of an intralesional platinum(II) delivery system, in which hyaluronan-conjugated cisplatin $\left(\mathrm{HylaPlat}^{\mathrm{TM}}\right.$ ) was administered intratumorally in laboratory mice with HNCs and pet dogs with spontaneous cancers including HNCs. The intralesional HylaPlat ${ }^{\mathrm{TM}}$ demonstrated sustained release and prolonged retention of platinum in the lesion and the surrounding lymphatic basin in mice and rats ${ }^{4-9}$, and a remarkably high ratio of platinum in the tumor tissues compared to the systemic circulation in $\operatorname{dogs}^{10}$. The improved targeted distribution of HylaPlat ${ }^{\mathrm{TM}}$ translated $^{1}$ into anti-cancer efficacy against HNCs in laboratory mice ${ }^{11-13}$ and in pet dogs with naturally occurring malignancies ${ }^{14,15}$. HylaPlat ${ }^{\mathrm{TM}}$ did not induce histologically evident injection-site reactions and systemic side effects such as renal and hepatic toxicities in rodents. Canine clinical studies, however, revealed myelosuppression, neutropenia, and liver injury, possibly due to the reactivity of the liberated platinum(II) from the loosely bound hyaluronan carriers in the form of diaquated cisplatin that subsequently entered circulatory system, bone marrow, and liver ${ }^{14}$. To improve the toxicology and the pharmacodynamics of intralesional platinum(II) therapy, an effective and safer platinum(IV) version of HylaPlat ${ }^{\mathrm{TM}}$ was developed.

Platinum(IV) chemistry has been sought by medicinal chemists for several decades and various mono-, di- and mixed axial-functionalized molecules have been synthesized as platinum(II) prodrugs ${ }^{16-19}$. The octahedrally coordinated platinum(IV) is more inert chemically than the planar platinum(II), making it more resistant to degradation and interactions with off-target biological substances in blood circulation and normal tissues before reaching the tumor site. However, partitioning and accumulation of drug in red blood cells, and subsequent hemoglobin Fe reduction to Pt(II) inactivates drugs such as Satraplatin $(\mathrm{JM} 216)^{20}$, which hinders their clinical use. To circumvent this shortcoming, we hypothesize that local, intralesional delivery of platinum(IV) directly to the tumor tissue may be advantageous. Once administered intratumorally, Pt(IV) accesses cancer cells that have a more reducing environment (e.g. in cytoplasm) and higher concentrations of reductants like ascorbic acid and glutathione, to which it binds, and is reduced to the active, DNA-damaging $\mathrm{Pt}(\mathrm{II})$ moieties ${ }^{19,21}$. Furthermore, the reduction potentials and reduction rates of $\mathrm{Pt}(\mathrm{IV})$ compounds could be tailored by installing different axial groups to the metal center. For example, carboxylato ligands display intermediate reduction potentials, whereas hydroxido 
ligands exhibit low and chlorido ligands exhibit high reduction potentials, which, in consequence, yield $\mathrm{Pt}(\mathrm{IV})$ molecules with different reactivity in vivo ${ }^{20,22}$.

In addition to improved kinetic stability, $\mathrm{Pt}(\mathrm{IV})$ may differ from $\mathrm{Pt}(\mathrm{II})$ in its mechanism of action. Traditionally, it is well recognized that platinum agents form Pt-DNA adducts and cause inhibition in protein biosynthesis which lead to apoptotic death of cancer cells. Moreover, Pt(IV) treatment was also shown to induce immunogenic cell death (ICD) and trigger massive infiltration of cytotoxic $\mathrm{CD} 8^{+} \mathrm{T}$ lymphocytes in colon cancer ${ }^{23}$. In contrast to a non-immunogenic cell death, ICD activates the host's immune system against the invading cancer. The dying cancer cells undergo several immunogenic processes, including calreticulin translocation to the cell surface, release of ATP and HMGB1, and generation of onco-antigens, that collectively result in the maturation of dendritic cells and the activation of T lymphocytes ${ }^{24,25}$. Similar findings were reported for oxaliplatin ${ }^{24,26}$, a Pt(II) agent with a bidentate ligand that shares structure similarity with Pt(IV) molecules. Accordingly, we hypothesize that a carrier-based Pt(IV) complex could elicit immunogenic cell death in a similar manner once the $\mathrm{Pt}(\mathrm{IV})$ cargo enters the cancer cells, resides and activates in the reductive cytoplasm.

\section{Materials and Methods}

Cis-Dichlorodiamine platinum (II) (cisplatin) was purchased from Strem Chemicals, Inc. (Newburyport, MA). Sodium hyaluronate was purchased from Contipro Inc (Dolní Dobrouč, Czech Republic). 1-[Bis(dimethylamino)methylene]-1H-1,2,3-triazolo[4,5-b]pyridinium 3oxide hexafluorophosphate (HATU), and 3-(3-Dimethylaminopropyl)-1-ethyl-carbodiimide hydrochloride (EDC-HCl) was purchased from Chem-Impex International, Inc. (Wood Dale, IL). 1-Hydroxybenzotriazole hydrate $\left(\mathrm{HOBt} \bullet \mathrm{H}_{2} \mathrm{O}\right)$ was purchased from Advanced ChemTech (Louisville, KY). $N$-(tert-Butoxycarbonyl)glycine (Boc-Gly-OH), hydrogen peroxide solution $\left(\mathrm{H}_{2} \mathrm{O}_{2}, 30\right.$ wt. $\%$ in $\left.\mathrm{H}_{2} \mathrm{O}\right)$, succinic anhydride, ( \pm )-a-tocopherol, $N, N^{\prime}$ Dicyclohexylcarbodiimide (DCC), $N, N$-Dimethylpyridin-4-amine (DMAP), trifluoroacetic acid (TFA), $N, N$-Diisopropylethylamine (DIPEA), oxaliplatin, tetrabutylammonium hydroxide solution (TBA-OH, $40 \mathrm{wt} . \%$ in $\mathrm{H}_{2} \mathrm{O}$ ), and anhydrous organic solvents were purchased from Sigma-Aldrich (Saint Louis, MO). Alexa Fluor ${ }^{\circledR} 488$ anti-CD8a, Alexa Fluor® 594 anti-CD11b, and Alexa Fluor® 647 anti-CD11c antibodies were purchased from BioLegend (San Diego, CA). All other chemicals and organic solvents were purchased from Thermo Fisher Scientific (Waltham, MA).

\section{Synthesis of Pt(IV)-Tocopherol [Pt(IV)-Toco] conjugate, (4)}

The synthetic scheme is shown in Figure 1. A bi-conjugated tocopherol $\mathrm{Pt}(\mathrm{IV})$ was reported by Suntharalingam et $\mathrm{al}^{27}$, in which doubly substituted $\mathrm{Pt}(\mathrm{IV})(\text { toco })_{2}$ and $\mathrm{Pt}(\mathrm{IV})($ toco)(OEt) were synthesized. Different from the reported molecules, we found that an axial substitution with a single tocopherol and a simple hydroxyl placement at the opposite axial position renders the characteristics needed for further fabrication of the carrier-based prodrug without the additional lipophilicity and bulk. 


\subsection{Synthesis of cis, cis, trans-[Pt( $\left.\left(\mathrm{NH}_{3}\right)_{2} \mathrm{Cl}_{2}(\mathrm{OH})_{2}\right],(1)$}

Fifty milliliter of $\mathrm{H}_{2} \mathrm{O}_{2}$ (30 wt \% in water) was added dropwise to a stirred suspension of cisplatin $(1.05 \mathrm{mg})$ in $3 \mathrm{~mL}$ of water $\left(50^{\circ} \mathrm{C}\right)$ in the dark. After 1 hour, a light-yellow suspension was obtained and subjected to recrystallization at $4{ }^{\circ} \mathrm{C}$ overnight. The product was collected by filtration, sequentially washed with ice-cold water, ethanol and diethyl ether, and dried under vacuum. A bright yellow solid was obtained as a product (95\% yield).

\subsection{Synthesis of cis, cis, trans-[Pt( $\left.\mathrm{NH}_{3}\right)_{2} \mathrm{Cl}_{2}\left(\mathrm{OOCCH} \mathrm{CH}_{2} \mathrm{CH}_{2} \mathrm{COOH}(\mathrm{OH})\right](\mathrm{Pt}(\mathrm{IV})-\mathrm{Su}, 2)$}

A suspension of compound 1 (200 mg, $0.60 \mathrm{mmol})$ and succinic anhydride $(66 \mathrm{mg}, 0.66$ mmol) in 16-mL of anhydrous DMSO was stirred in the dark at $25^{\circ} \mathrm{C}$ overnight and resulted in a clear light yellowish solution. After DMSO was removed by lyophilization (Labconco 2.5 Plus FreeZone, Kansas City, MO), the product was obtained by recrystallization from acetone at $-20{ }^{\circ} \mathrm{C}$ overnight, and washed with cold acetone and diethyl ether. The solid was dried under vacuum and was a pale yellow product $(70 \%) .{ }^{1} \mathrm{H}$ NMR $\left(400 \mathrm{MHz}\right.$, DMSO- $\left.d_{6}\right)$ $\delta$ 6.24-5.66 (m, 6H), 2.34-2.45 (m, 4H), (Figure S1).

\subsection{Synthesis of H-Gly-Tocopherol (H-Gly-Toco, 3)}

Boc-Gly-OH (0.89 g, $5.11 \mathrm{mmol}),( \pm)$-a-tocopherol $(2.42 \mathrm{~g}, 5.62 \mathrm{mmol})$, and DMAP (64 $\mathrm{mg}, 0.52 \mathrm{mmol}$ ) were dissolved in $20-\mathrm{mL}$ of anhydrous DCM. The mixture was added dropwise to a solution of DCC $(1.16 \mathrm{~g}, 5.62 \mathrm{mmol})$ in $5-\mathrm{mL}$ of anhydrous DCM, and was stirred at room temperature overnight. The reaction mixture was then stored at $-20{ }^{\circ} \mathrm{C}$ for 2 hours. After the white precipitate was filtered off, solvent was removed under vacuum to obtain a pale-yellow syrup. The product was purified by a Combiflash $\mathrm{Rf}+$ purification system (Teledyne ISCO, Lincoln, NE), and eluted at 5\% v/v of EtOAc in hexane. The product fractions were concentrated under vacuum to obtain a colorless syrup ( $92 \%$ yield).

${ }^{1} \mathrm{HNMR}(400 \mathrm{MHz}$, Chloroform- $d$ ) $\delta 5.17(\mathrm{~s}, 1 \mathrm{H}), 4.21(\mathrm{~d}, J=5.0 \mathrm{~Hz}, 2 \mathrm{H}), 2.59$ (t, $J=6.8$ $\mathrm{Hz}, 2 \mathrm{H}$ ), 2.10 (s, 3H), 2.02 (s, 3H), 1.98 (s, 3H), 1.79 (ddq, $J=20.0,13.3,6.8 \mathrm{~Hz}, 2 \mathrm{H}$ ), $1.63-1.49(\mathrm{~m}, 3 \mathrm{H}), 1.49-1.45(\mathrm{~m}, 9 \mathrm{H}), 1.38(\mathrm{qd}, J=8.4,7.5,3.0 \mathrm{~Hz}, 4 \mathrm{H}), 1.31-1.18(\mathrm{~m}$, $11 \mathrm{H}), 1.17-1.02(\mathrm{~m}, 6 \mathrm{H}), 0.87(\mathrm{~d}, J=6.6 \mathrm{~Hz}, 6 \mathrm{H}), 0.85-0.83(\mathrm{~m}, 6 \mathrm{H})($ Figure $\mathrm{S} 2) ;{ }^{13} \mathrm{C}$ NMR (101 MHz, $\left.\mathrm{CDCl}_{3}\right) \delta 169.31,155.83,149.78,140.30,126.71,125.00,123.33,117.64$, $80.24,75.28,42.47,39.52,37.70,37.61,37.56,37.54,37.44,32.93,32.85,31.17,28.46$, 28.13, 24.96, 24.59, 22.87, 22.77, 21.17, 20.73, 19.90, 19.83, 13.12, 12.27, 11.96. (Figure S3); Chemical formula: $\mathrm{C}_{36} \mathrm{H}_{61} \mathrm{NO}_{5}$. ESI-MS: $\mathrm{M}+\mathrm{Na}^{+}=610.4447$, found 610.4444 .

A solution of TFA $(5 \mathrm{~mL})$ in DCM $(5 \mathrm{~mL})$ was added dropwise into a solution of Boc-GlyToco $(2.87 \mathrm{~g}, 4.89 \mathrm{mmol})$ in DCM $(15 \mathrm{~mL})$ at $0{ }^{\circ} \mathrm{C}$ for $30 \mathrm{~min}$, and the reaction mixture was stirred at ambient temperature overnight. The reaction mixture was evaporated under vacuum, and the resulting gray solid was purified over silica. The product (H-Gly-Toco, 3) fractions yielded a white solid after concentration under vacuum (yield 60\%). ${ }^{1} \mathrm{H}$ NMR (400 MHz, DMSO- $\left.d_{6}\right) \delta 8.45(\mathrm{~s}, 2 \mathrm{H}), 4.27(\mathrm{~s}, 2 \mathrm{H}), 2.57(\mathrm{t}, J=6.9 \mathrm{~Hz}, 2 \mathrm{H}), 2.04(\mathrm{~s}, 3 \mathrm{H}), 1.97(\mathrm{~s}$, $3 \mathrm{H}), 1.95(\mathrm{~s}, 3 \mathrm{H}), 1.81-1.72(\mathrm{~m}, 2 \mathrm{H}), 1.56-1.44(\mathrm{~m}, 3 \mathrm{H}), 1.40(\mathrm{t}, J=8.7 \mathrm{~Hz}, 4 \mathrm{H}), 1.31-1.16$ $(\mathrm{m}, 11 \mathrm{H}), 1.16-0.99(\mathrm{~m}, 6 \mathrm{H}), 0.83(\mathrm{dd}, J=9.1,6.5 \mathrm{~Hz}, 12 \mathrm{H})$, (Figure S4); ${ }^{13} \mathrm{C}$ NMR $(101$ MHz, DMSO) $\delta 166.76,149.01,139.57,126.21,124.91,122.07,117.59,74.95,36.73$, $36.58,32.04,31.93,27.37,24.13,23.69,22.54,22.45,20.31,19.87,19.61,19.55,12.77$, 
11.91, 11.56, (Figure S5). Chemical formula: $\mathrm{C}_{31} \mathrm{H}_{53} \mathrm{NO}_{3}$. ESI-MS: $\mathrm{M}+\mathrm{H}^{+}=487.4025$, found 487.4106 .

\subsection{Synthesis of Pt(IV)-Su-Gly-Toco (Pt(IV)-Toco, 4)}

A mixture of Pt(IV)-Su (0.54 g, $1.25 \mathrm{mmol})$, HATU (0.71 g, $1.87 \mathrm{mmol})$, and DIPEA (0.43 $\mathrm{ml}, 2.47 \mathrm{mmol}$ ) in $30 \mathrm{~mL}$ of anhydrous DMSO was added to a solution of H-Gly-Toco (0.62 $\mathrm{g}, 1.28 \mathrm{mmol}$ ) in DMSO and stirred overnight. The DMSO was removed under reduced pressure, and the resulting oily mixture was purified by the Combiflash $\mathrm{Rf}+$ system eluting at $0 \%$ to $20 \%$ of $\mathrm{MeOH}$ in DCM. The product fractions were concentrated under vacuum to a brown solid, and subsequently washed with $\mathrm{MeOH}$ to obtain the product as a beige solid (25\%). ${ }^{1} \mathrm{H}$ NMR (400 MHz, DMSO- $\left.d_{6}\right) \delta 8.47(\mathrm{dt}, J=16.9,5.9 \mathrm{~Hz}, 1 \mathrm{H}), 6.17-5.62(\mathrm{~m}$, $6 \mathrm{H}), 4.14(\mathrm{t}, J=5.0 \mathrm{~Hz}, 2 \mathrm{H}), 2.63-2.52(\mathrm{~m}, 3 \mathrm{H}), 2.48-2.35(\mathrm{~m}, 4 \mathrm{H}), 2.02(\mathrm{~s}, 3 \mathrm{H}), 1.93(\mathrm{~s}$, $3 \mathrm{H}), 1.91(\mathrm{~s}, 3 \mathrm{H}), 1.76(\mathrm{t}, J=7.7 \mathrm{~Hz}, 2 \mathrm{H}), 1.51$ (dt, $J=13.1,6.5 \mathrm{~Hz}, 3 \mathrm{H}), 1.44-1.34(\mathrm{~m}$, $4 \mathrm{H}), 1.32-1.17(\mathrm{~m}, 11 \mathrm{H}), 1.17-1.02(\mathrm{~m}, 6 \mathrm{H}), 0.92-0.80$ (m, 12H), (Figure S6).

\section{Synthesis of Hyaluronan-Tocopherol (HA-Toco) conjugate}

\subsection{Synthesis of HA-TBA, (5)}

Sodium hyaluronate $(32 \mathrm{kDa}, 10 \mathrm{~g}$ ) was dissolved in $200 \mathrm{~mL}$ of water, and stirred for 1 hour. The solution was added to $50 \mathrm{~g}$ of AG 50W-X8 cation-exchange resin (20-50 mesh, H-form, Bio-Rad, Hercules, CA), and stirred overnight. The mixture was filtered, and the filtrate was titrated with TBA-OH to $\mathrm{pH} 8-9$. The aqueous solution was lyophilized to obtain a white sponge-like cake and was stored at $-20{ }^{\circ} \mathrm{C}$ for future use (Yield $64 \%$ ).

\subsection{Synthesis and characterization of HA-Toco, (6)}

A solution of HA-TBA ( $200 \mathrm{mg}, 0.32 \mathrm{mmol}$ ) in $12 \mathrm{~mL}$ of DMF was stirred for $30 \mathrm{~min}$ at ambient temperature (ca. $20^{\circ} \mathrm{C}$ ). A mixture of H-Gly-Toco (15.6 mg, $0.032 \mathrm{mmol}$ ), EDC (15.4 mg, $0.08 \mathrm{mmol}$ ), and $\mathrm{HOBt} \bullet \mathrm{H}_{2} \mathrm{O}(7.4 \mathrm{mg}, 0.048 \mathrm{mmol})$ in $2.3 \mathrm{~mL}$ of DMF was added to the previous solution at ambient temperature and stirred overnight. The reaction mixture was dialyzed using regenerated cellulose dialysis tubing (10,000 MWCO, Thermo scientific) against 50 vol.\% EtOH in water overnight, then against $\mathrm{NaCl}$ dialysate $(150 \mathrm{mM}, 2$ changes in 24 hours), and subsequently against water ( 3 changes in 2 days). The dialyzed mixture was lyophilized to yield a white cotton-like polymer 6 (117 mg, yield 69\%). The degree of substitution (SD) of tocopherol molecules on HA was calculated to be ca. $6 \%$ on a molar basis by comparing the peak integration ratio of the $\mathrm{N}$-acetyl group of $\mathrm{HA}(\mathrm{s}, 3 \mathrm{H}, 2.02 \mathrm{ppm})$ to the methyl groups of tocopherol ( $\mathrm{m}, 12 \mathrm{H}, 0.81-0.86 \mathrm{ppm}$ ) in ${ }^{1} \mathrm{HNMR}$ spectra (Figure S7). The hydrodynamic diameter of HA-Toco in an aqueous solution was determined using a ZetaPALS (Brookhaven Instrument Corporation, Holtsville, NY). All measurements were carried out with five replicates.

\section{Preparation of HA-Toco/Pt(IV)-Toco complex}

HA-Toco (122 mg) was rehydrated in $12 \mathrm{~mL}$ of water on a shaker overnight. To the HAToco solution, a solution of Pt-Toco (61 mg) in $2.4 \mathrm{~mL}$ of DMSO was added dropwise, and the resulting mixture was stirred for 2 hours in the dark. The solution was lyophilized 
overnight to remove water and DMSO, then the solid was rehydrated with $5 \mathrm{~mL}$ of water for injection (WFI) into a homogenous nanosuspension. The Pt concentration was determined by an inductively coupled plasma-mass spectrometry (ICP-MS, Agilent Technologies 7500i, Santa Clara, CA) using terbium as the internal standard ${ }^{28}$. High purity argon $(>99.996 \%)$ was used as the carrier gas. The final drug concentration was calculated on a cisplatin weight basis. The loading degree of $\mathrm{Pt}$ on $\mathrm{HA}-\mathrm{Toco} / \mathrm{Pt}(\mathrm{IV})-\mathrm{Toco}$ is approximately $10 \%$. Note: for simplicity, the HA-Toco/Pt(IV)-Toco is abbreviated as HA-Pt(IV) in this article.

\section{In vitro studies}

\subsection{AT84 cells}

AT84 cells were derived from a spontaneous squamous cell carcinoma in the oral mucosa of a C3H mouse ${ }^{29,} 30$ and were gifted by Aldo Venuti (Regina Elena National Cancer Institute, Rome, Italy). Cells tested negative for interspecies contamination (Idexx BioResearch) and rodent pathogens (21 pathogen IMPACT I PCR profile), and negative for Mycoplasm contamination prior to animal studies (Lonza, MycoAlert test kit). Idexx CellCheck STR (short tandem repeat) profile: MCA-4-2: 20.3, 21.3; MCA-5-5: 15; MCA-6-4: 18, 19; MCA-6-7: 12; MCA-9-2: 15; MCA-12-1: 16; MCA-15-3: 25.3, 26.3; MCA-18-3: 16; MCAX-1: 26, 27. Cells were cultured in RPMI-1640 media (Gibco, Thermo Fisher Scientific, Waltham, MA) supplemented with 10\% FBS (Corning Corning, NY), $100 \mathrm{U} / \mathrm{mL}$ penicillin, and $100 \mu \mathrm{g} / \mathrm{mL}$ streptomycin (HyClone, Thermo Fisher Scientific, Waltham, MA) in a humidified incubator at $37^{\circ} \mathrm{C}$ and $5 \% \mathrm{CO}_{2}$.

\subsection{Anti-proliferation}

AT84 cells were seeded into 96-well plates (3,000 cells/well) and allowed to attach overnight. Cisplatin and HA-Pt(IV) were diluted in water and added to the cells (8 concentrations in duplicate). After 72 hours at $37^{\circ} \mathrm{C}$, Resazurin Blue (Acros Organics, Geel, Belgium) in PBS was added to each well ( $5 \mu \mathrm{M}$ final concentration) and incubated at $37^{\circ} \mathrm{C}$ for 4 hours. Fluorescence $\left(\lambda_{\mathrm{ex}} 550 \mathrm{~nm}, \lambda_{\mathrm{em}} 605 \mathrm{~nm}\right.$ ) was quantified with a SpectraMax Gemini XS plate-reader (Molecular Devices, Sunnyvale, CA). The relative growth of cells incubated with each compound concentration was normalized to vehicle-treated controls (100\% proliferation). Data from at least three separate experiments were analyzed using non-linear regression (GraphPad Prism 5.0) to generate $\mathrm{IC}_{50}$ values.

\subsection{Calreticulin translocation}

Plasmid: A mouse calreticulin-HaloTag ${ }^{\circledR}$-KDEL fusion protein (reported by Golden et al. ${ }^{31}$ ) was synthesized (ATUM, Newark, CA) and inserted into the pD643 mammalian expression vector having a CayenneRFP fluorescent reporter gene (Ex:554nm / Em:590nm) (Addgene, Watertown, MA, USA, plasmid \#153529). The resulting construct was sequenced to confirm the insert.

AT84 cells were plated in 6-well culture plates and allowed to grow to $90 \%$ confluence. Cells were transfected with the calreticulin plasmid with lipofectamine (Invitrogen, Carlsbad, CA) using $10 \mu \mathrm{g} / \mathrm{well} \mathrm{pDNA}$. After 5 hours at $37^{\circ} \mathrm{C}$, cells were split 1:3 into 6well plates with complete media and incubated overnight at $37^{\circ} \mathrm{C}$. Cisplatin, oxaliplatin, or 
HA-Pt(IV) was added to a final concentration of $500 \mu \mathrm{M}$ (drug). Following 12-15 hours incubation, cells were washed with fresh media. Cells were incubated at $37^{\circ} \mathrm{C}$ for 30 minutes with $1 \mu \mathrm{M}$ HaloTag ${ }^{\circledR}$ Alexa Fluor ${ }^{\circledR} 488$ Ligand (1 mM solution, Promega, Madison, WI) and $20 \mu \mathrm{M}$ Hoechst dye (20 mM solution, Thermo Scientific, Rockford, IL), washed with media, and imaged within one hour. Live cells were imaged using an Olympus IX81 inverted epifluorescence microscope with a 60x objective. Representative images are shown from 3 independent experiments (Figure 4).

\section{In vivo studies}

\subsection{Mice}

All rodent studies were performed at the University of Kansas Animal Care Unit, which is in compliance with the "Guide for the Care and Use of Laboratory Animals" and is accredited by the Association for the Assessment and Accreditation of Laboratory Animal Care International (AAALAC). The studies were done according to a protocol approved by the University of Kansas IACUC committee.

\subsection{Immuno-competent tumor model for efficacy}

Wildtype male and female C3H mice (Charles River Strain 025, 6-8 weeks old, 20-25g) were used for in vivo tumor studies. Since no differences were found between the sexes, the reported results combined both sexes into one group. Mice were anesthetized using 5\% isoflurane in $\mathrm{O}_{2}$ for 5 minutes. One million AT84 cells in $50 \mu \mathrm{PBS}$ were injected subcutaneous (s.c.) into the floor of the mouth via an extra-oral route of $\mathrm{C} 3 \mathrm{H}$ mice to obtain orthotopic allograft tumors ${ }^{29,30}$. Treatment began when tumors reached $75 \mathrm{~mm}^{3}$, generally on days 4 to 7 after cell injection. Under isoflurane anesthesia, HA-Pt(IV) (3 mg/kg Pt(IV) basis) or vehicle ( $50 \mu \mathrm{l}$ hyaluronan-tocopherol, $16.7 \mathrm{mg} / \mathrm{mL})$ was injected intratumoral once per week for 3 weeks. Tumor size was calculated: tumor volume $\left(\mathrm{mm}^{3}\right)=4 \pi / 3 \times(\text { width } / 2)^{2}$ $\times(\text { length } / 2)^{32}$, where length is the longer of two perpendicular dimensions. Statistical comparisons were conducted using GraphPad Prism v.7 software (San Diego, CA).

\subsection{Immuno-deficient tumor model for efficacy}

Nude male and female mice (Charles River Ath/nu, 6-8 weeks old, 20-25g) were used for in vivo xenograft studies. Since no differences were found between the sexes, results show both sexes as one group. Mice were anesthetized using 5\% isoflurane in $\mathrm{O}_{2}$ for 5 minutes. One million MDA-1986 cells in $50 \mu \mathrm{l}$ PBS were injected subcutaneously into the left cheek of mice to obtain orthotopic xenograft tumors ${ }^{11,13}$. Treatment began when tumors reached 75 $\mathrm{mm}^{3}$, generally on day 14 after cell injections. Under isoflurane anesthesia, HA-Pt(IV) (3 $\mathrm{mg} / \mathrm{kg}$ Pt(IV) basis) or vehicle (1.5 MDa hyaluronan, $16.7 \mathrm{mg} / \mathrm{mL}$ ) was injected intratumoral once per week for 3 weeks. Tumor size and statistical comparisons were performed as stated in the $\mathrm{C} 3 \mathrm{H}$ model.

\subsection{Tumor stains using immune cell markers}

Mice with AT84 derived head and neck tumors were randomly divided into 5 groups, including 1) no treatment, 2) three weekly intravenous cisplatin injection $(3 \mathrm{mg} / \mathrm{kg}$ per dose), 3) one intratumoral HA-Pt(IV) injection (3 mg/kg), 4) two weekly intratumoral HA- 
$\mathrm{Pt}(\mathrm{IV})$ injections (3 $\mathrm{mg} / \mathrm{kg}$ per dose), and 5) three weekly intratumoral HA-Pt(IV) injections ( $3 \mathrm{mg} / \mathrm{kg}$ per dose). Our previous studies showed that intravenous cisplatin penetrated tumors inadequately and cleared rapidly from the systemic circulation, so IV cisplatin was administered as a triple-dose treatment instead of a double- or single-dose treatment. All mice, except for the no treatment group, were sacrificed after the last injection. The individual tumors were excised and frozen in OCT medium. The embedded tumors were sectioned into $20 \mu \mathrm{m}$ slices on a Shandon Cryotome ${ }^{\circledR}$ FSE (Thermo Scientific). The sections were fixed in 10\% formalin for 15 minutes, blocked with $5 \%$ goat serum in PBS, and stained with primary antibodies. Fluorescent-dye conjugated primary antibodies were diluted to 5 $\mu \mathrm{g} / \mathrm{mL}$ in blocking buffer ( $5 \%$ goat serum in PBS) and incubated overnight at $4{ }^{\circ} \mathrm{C}$. After antibody staining, sections were stained with $10 \mu \mathrm{g} / \mathrm{mL}$ Hoechst 33342 for 15 minutes, mounted in SouthernBiotech ${ }^{\mathrm{TM}}$ Fluoromount $-\mathrm{G}^{\mathrm{TM}}$ Slide Mounting Medium, and stored in the dark at $4{ }^{\circ} \mathrm{C}$. Images were acquired using an Olympus IX-81 inverted epifluorescence microscope at 10x magnification. The acquired images were compiled on Slidebook 6.0.

\subsection{RNA isolation}

Tumor pieces were stored in RNAlater solution at room temperature for at least one day and then at $4{ }^{\circ} \mathrm{C}$ until RNA isolation. Tumor pieces were removed from RNAlater solution and homogenized in $10 \mathrm{~mL}$ TRIzol reagent (38\% phenol, $0.8 \mathrm{M}$ guanidine thiocyanate, $0.4 \mathrm{M}$ ammonium thiocyanate, $0.1 \mathrm{M}$ sodium acetate, $5 \%$ glycerol). Homogenate was divided into $1 \mathrm{~mL}$ aliquots for ease of subsequent centrifugation steps. To each $1 \mathrm{~mL}$ of homogenate, 100 $\mu \mathrm{BCP}$ (Molecular Research Center, Cincinnati, $\mathrm{OH}$ ) was added, shaken vigorously 15 seconds and centrifuged $12,000 \times \mathrm{g}, 10$ minutes, $4^{\circ} \mathrm{C}$. Top aqueous layer contains RNA, which is precipitated with isopropanol and washed with $75 \%$ ethanol. RNA was reconstituted in $1 \mathrm{mM}$ sodium citrate $\mathrm{pH} 6.4$ and stored at $-80^{\circ} \mathrm{C}$. RNA quality was analyzed using the Agilent TapeStation; all RNA samples showed an RNA integrity number greater than 8 , which is indicative of excellent quality.

\subsection{RNA sequencing}

Sequencing was performed on an Illumina NextSeq 550 in the SR-75 mode (KU Genome Sequencing Core). Three reads from each demultiplexed sample were combined and checked for quality in FastQC v0.11.8. ${ }^{33}$ The expression of the transcripts was quantified using Salmon v.1.0.0 with an index compiled from the Mus musculus GRCm38 primary assembly and transcriptome. ${ }^{34,35}$ The transcript abundance estimates from Salmon was converted into gene-level count matrices using tximport v.1.14.2. ${ }^{36}$ Count normalization was performed using DESeq2 v.1.26.0., and data was filtered by $p$-value $<0.1$ and $\log 2$ fold change $(\mathrm{LFC})>1.58$ to obtain genes with most significant differences in expression between control and Pt4-treated tumors. Gene ontology (GO) and Kyoto Encyclopedia of Genes and Genomes (KEGG) pathways clustering analysis was performed on the expression data using Gene Set Enrichment Analysis (GSEA) v 3.0.0 37, 38 . Sequence data and sample descriptions are available at NCBI BioProject accession \#PRJNA612618. 


\section{Results and Discussion}

The carrier-based HA-Pt(IV) was developed first by functionalizing one of the axial ligands of the platinum with activated tocopherol via a succinic linkage. Subsequently, the derivatized lipophilic $\mathrm{Pt}(\mathrm{IV})$ molecule was complexed with a hyaluronan-tocopherol conjugate via attractions between the lipophilic tocopherol portions of the two molecules, forming a hyaluronic acid polymer-based delivery platform for the anticancer $\mathrm{Pt}(\mathrm{IV})$ cargo. A Pt(IV)-based oncology molecule is of interest in this study due to its less toxic nature than the platinum(II) compounds as a result of the altered reduction kinetics of the platinum(IV $)^{39}$, making them less likely to cause dose-limiting side effects as seen in cisplatin, as well as due to its improved cellular accumulation and greater lipophilicity, a property facilitating the encapsulation or complexation into nanocarriers ${ }^{21}$. Lippard et al. at MIT reported several derivatives of Pt(IV) that utilized tocopherol or fatty acids to encapsulate the drugs in micelles or form other prodrugs ${ }^{27,40}$. $\mathrm{Pt}(\mathrm{IV})$-containing nanoconjugates such as dextranplatinum(IV) and ethylenediamine modified hyaluronic acidplatinum(IV) were also reported by other groups and underwent preclinical development ${ }^{41,42}$.

Based on our experience with carrier-based Pt(II) drugs, we hypothesized that localized delivery to tumor would further improve the activity of Pt(IV). In addition, we believed a hyaluronan-based carrier could increase retention and tumor-associated lymph node uptake, while lessening RBC inactivation, a drawback of previous unsuccessful Pt(IV) molecules including the clinically investigated drug Sartaplatin. ${ }^{43}, 44$ The uniqueness of the HA-Pt(IV) formulation in this work is manifested by the combination of at least three factors including - a lipophilic platinum(IV) and its immunological properties as discussed below, a safe and pharmacokinetically tailored hyaluronan-based drug carrier demonstrated by previous animal studies ${ }^{7-9}, 11,13,45-47$, and a clinically feasible mode of intralesional delivery for spontaneous cancers based on the results of canine clinical trials ${ }^{10,14,15}$. The HA-Pt(IV) formulation uses FDA-designated generally recognized as safe (GRAS) substances such as a-tocopherol, and biodegradable and biocompatible natural polysaccharide such as hyaluronic acid, which has been approved by the FDA for uses as a dermal filler and as an intra-articular injection. These characteristics render HA-Pt(IV) a clinically relevant molecule and justify the synthetic and testing efforts, which are discussed below in detail.

\section{Hydrodynamic diameter of HA-Toco}

The hydrodynamic diameter of HA-Toco in water solution was determined to be $332.0 \pm 2.2$ $\mathrm{nm}$ with a polydispersity of $0.145 \pm 0.028$ using the intensity weighted Gaussian distribution. The particle size of tocopherol functionalized hyaluronan nanoparticles was much larger than the non-tocopherol conjugated hyaluronic acid molecules previously evaluated by the authors $(25.2 \pm 4.4 \mathrm{~nm})^{48}$. The formation of larger particles can be attributed to the intra- and inter-molecular interactions between the hydrophobic tocopherol pedants, tangling the long and linear HA chains. These HA-toco nanoparticles further attract small-molecule Pt(IV)-tocopherol and eventually construct drug-retaining depots that can release $\mathrm{Pt}(\mathrm{IV})$ and cause growth inhibition of cancer cells. 


\section{In vitro studies}

\subsection{Anti-proliferation}

To determine whether HA-Pt(IV) exhibits anti-proliferative activity against cancer cells, it was tested for growth inhibition of the AT84 murine head and neck cancer cell line (Figure 3 ) and the human MDA-1986 head and neck cancer cells. The positive control, cisplatin, and HA-Pt(IV) both inhibited over $80 \%$ of cell growth compared to vehicle-treated controls at the highest doses tested with potencies $\left(\mathrm{IC}_{50}\right)$ of $3.0 \pm 0.26 \mu \mathrm{M}$ and $6.1 \pm 1.1 \mu \mathrm{M}$, respectively. Oxaliplatin also inhibits growth of these cells with slightly lower potency (13.6 $\pm 3.8 \mu \mathrm{M})$. The results suggest that the HA-Pt(IV) complexes demonstrated similar growth inhibition against cancer cells compared to cisplatin, enabling further mechanistic evaluation such as the calreticulin translocation assay discussed below.

\subsection{Calreticulin translocation}

The immunological effects induced by certain anticancer chemotherapeutics began to divert the interest of developers of conventional chemotherapies due to their pathways for the activation of the immune system against the cancer. Chemotherapy can induce cell death that can be either immunological or non-immunological. Cisplatin causes non-immunogenic cell death, wherein apoptotic cell debris is cleared by macrophages without the activation of dendritic cells or the release of significant levels of pro-inflammatory cytokines such as IL12 and $\mathrm{TNFa}^{49}$, while other chemotherapies, such as oxaliplatin, cause immunologic cell death $^{24,25,50,51}$. ICD is a particular type of apoptotic cancer cell death that activates the host immune system ${ }^{24,52}$ against tumor cells. Some chemotherapeutics elicit ICD by creating endoplasmic reticulum stress, leading to membrane translocation of calreticulin (CRT), an early indicator of ICD, which can be tested in vitro ${ }^{31,52}$. Other characteristics of ICD include release of ATP and high mobility group protein 1, which activates dendritic cells to present tumor antigens to the cytotoxic $\mathrm{CD}^{+} \mathrm{T}$ lymphocytes to complete the final destruction of tumor cells ${ }^{25}$. Unlike traditional chemotherapeutics, which rely on the penetration of nonimmunogenic cytotoxins and sustained exposure, immunogenic chemotherapeutics like oxaliplatin and Pt(IV) may elicit a tumor-specific immune response $^{23}$.

In the calreticulin translocation assay, AT84 cells were transfected with a plasmid coding for mouse CRT-HaloTag ${ }^{\circledR}$-KDEL fusion protein. Positivity transfected cells were identified by visualizing the CayenneRFP reporter protein (red), coded for in the same plasmid. Following overnight treatment with an ICD-inducing drug, CRT translocates to the plasma membrane, exposing the HaloTag ${ }^{\circledR}$ protein to the outside of the cell. Extracellularly exposed HaloTag ${ }^{\circledR}$ protein can bind to the membrane impermeable HaloTag ${ }^{\circledR}$ Ligand Alexa Fluor ${ }^{\circledR} 488$. After overnight treatment with the positive control, oxaliplatin $(500 \mu \mathrm{M})^{25}$, membrane translocation of CRT is observed as green fluorescence (Figure 4). Similar to oxaliplatin, $\mathrm{Pt}(\mathrm{IV})(500 \mu \mathrm{M})$ also causes CRT translocation to the membrane, indicating ICD. In contrast, cisplatin does not cause CRT translocation to the membrane, thus unavailable to bind the 488-labled ligand (no green), indicating a lack of ICD, consistent with previous reports ${ }^{53}$. In an oversimplified sense, the immunogenic oxaliplatin and hopefully the newly developed HA-Pt(IV) could be regarded mechanistically as the equivalent of cisplatin plus 
radiation therapy in terms of inducing ICD (cisplatin does not induce ICD, but irradiation does), which explains their superior potential for long-term success in a realistic tumor model (e.g. immunocompetent small laboratory animals, such as $\mathrm{C} 3 \mathrm{H}$ mice, or large nonlaboratory animals, such as dogs). While in vitro translocation of CRT is an indicator of ICD, analysis of in vivo tumor response and immune response (cell types, pro-inflammatory cytokines, etc.) in an intact animal is required to understand ICD mechanisms. We have begun these in vivo analyses in this report; more detailed analyses of the ICD immune response remain an active area of investigation in our lab.

\section{In vivo studies}

\subsection{Mouse tumor efficacy}

We used two models of head and neck cancer to determine whether HA-Pt(IV) can inhibit tumor growth in vivo. One model uses a spontaneously arising oral squamous cell cancer (AT84) in immunocompetent $\mathrm{C} 3 \mathrm{H}$ mice, while the other model uses human derived cervical nodal metastasis of tongue cancer (MDA1986) in immunodeficient athymic nude mice. C3H mice with AT84 allografts and nude mice with MDA1986 xenografts were administered HA-Pt(IV) ( $3 \mathrm{mg} / \mathrm{kg})$ intratumorally once per week for 3 weeks, starting when the tumor reached $\sim 75 \mathrm{~mm}^{3}$. These doses were empirically determined as tolerable in these mice, resulting in no decrease in weight or deterioration in body condition.

In both tumor models, HA-Pt(IV) treatments significantly reduced tumor growth over the time course compared to vehicle treated animals in the control group (Figure 5). In the AT84 allografts, the mean \pm SEM for the final tumor measurements of the control and the HA$\mathrm{Pt}(\mathrm{IV})$ treated were $2027 \pm 364 \mathrm{~mm}^{3}$ and $1024 \pm 129 \mathrm{~mm}^{3}$, respectively, a $49 \%$ tumor inhibition in an immunocompetent host. On the other hand, the mean \pm SEM for the final measurements of the control and the HA-Pt(IV) treated were $1427 \pm 162 \mathrm{~mm}^{3}$ and $812 \pm 150$ $\mathrm{mm}^{3}$, respectively, in the MDA-1986 xenografts, a 43\% tumor inhibition in an immunodeficient host.

Though the difference in the percent tumor regression at the end of the study between the two models was relatively small, the AT84 model showed a difference in tumor growth between the control and the treated groups much earlier than the MDA1986 model. Specifically, AT84 tumors in immunocompetent mice were significantly smaller than controls between day 21 and 32, about one third of the entire study course. In contrast, MDA1986 tumors in immunodeficient mice were significantly smaller than controls between days 35 to 42 , only $17 \%$ of the entire study course. The superior efficacy in the AT84 model may be due to the ICD effect induced by the Pt(IV) treatment, which would only manifest in animals with an intact immune system. Pt(IV)-induced ICD may involve dendritic cell recruitment and $\mathrm{T}$ lymphocyte activation to attack and eradicate some of the residual cancer cells. Thus, the dying cancer cells may act as an immunogenic site to stimulate tumor-specific immune responses and sustain the effectiveness of the cytotoxic stimulus. Ongoing studies are examining immune cell responses to HA-Pt(IV) therapy. 


\subsection{Survival}

The HA-Pt(IV) treatment resulted in significantly increased survival in both tumor models (Figure 6). In the AT84 immunocompetent model, HA-Pt(IV) treatment resulted in a survival rate of $100 \%$ by the time all control mice died. In contrast, in the MDA1986 immunocompromised model, HA-Pt(IV) treatment showed only 50\% survival when all control mice died. The differences observed between the two models' efficacy and survival may be partially due to the immunogenic nature of the HA-Pt(IV), though the difference may also be attributed to the intrinsic characteristics of the two distinct tumor models and respective growth patterns. The human cancer cell line MDA1986, as opposed to the murine cancer cell line AT84, was selected to establish the tumor models in nude mice because the murine cancer cells could grow aggressively in immunodeficient mice and cause premature casualty, interfering with the validity of the study. Thus, the MDA1986 model was included for a more thorough examination of the immunological response in tumors.

\subsection{Tumor immunohistochemistry}

Tumor tissues were stained for the immunological markers CD8a, CD11b and CD11c, which are commonly recognized markers for cytotoxic $\mathrm{T}$ lymphocytes, macrophages, and dendritic cells, respectively. CD8a staining was observed after 2 and 3 weekly injections of HA-Pt(IV) (2x and $3 \mathrm{X})$, but not after the first injection (1X). A CD8+ cytotoxic T cell response can take up to 7 days to develop and was not observed 2 days after the first injection, when that group was sacrificed. For CD11c staining, all groups display a low intensity pattern for dendritic cells, suggesting a baseline level in all AT84 tumors. In contrast, the $\mathrm{CD} 11 \mathrm{~b}$ column demonstrates the most prominent differences between the no treatment and the HA-Pt(IV) treated groups $(1 \times, 2 \times$, or $3 \times)$; to a lesser degree, between the no treatment and the cisplatin $(3 \times)$ treated groups. The strongest intensity of fluorescence is detected in the $3 \times \mathrm{HA}-\mathrm{Pt}(\mathrm{IV})$ treated tumor sections, consistent with this group having the highest accumulated doses of Pt(IV). In addition, between the $3 \times \mathrm{HA}-\mathrm{Pt}(\mathrm{IV})$ and the $3 \times$ cisplatin treated tumors, the former appears to present a higher number of tumor-infiltrating macrophages than the latter.

Certain chemotherapeutics induce increased macrophage recruitment to tumor microenvironment ${ }^{54-56}$. As a consequence of the inherent plasticity of macrophages, they respond to local stimulants and allow two contradictory transformations, one resulting in an inflammatory, M1-polarized activation that inhibits tumor progression, while, the other, leading to a non-inflammatory, M2-polarized activation that promotes tumor invasiveness ${ }^{57,58}$. In this case, the corresponding local stimulants may either be the trace concentration of cisplatin, a fraction of its total intravenous dose that manages to diffuse into tumor from blood vessels, or the high concentration of HA-Pt(IV) nanoparticles, sustainably eluted from the injection depot, engulfed by the infiltrating macrophages via phagocytosis, and subsequently transported to the neighboring tumor cells. It is not surprising that the selfregulated uptake of $\mathrm{Pt}(\mathrm{IV})$ molecules and the simultaneous recruitment of macrophages could work synergistically to result in a superior tumor suppression compared to the intravenous cisplatin. Further investigations on the identity of the infiltrating macrophages using M1/M2 specific markers in the presence of fluorescently labeled, intratumorally 
administered HA-Pt(IV) may elucidate the dynamics of the tumor environment and the immune cell activation.

\subsection{RNA sequencing}

In the gene expression analysis, 35 genes in the HA-Pt(IV)-treated were filtered as differentially expressed compared to the untreated control, 20 of which were downregulated, whereas 15 of which were upregulated $(\mathrm{p}<0.1)$. If the analysis threshold was tightened to $\mathrm{p}<0.05,17$ genes in the HA-Pt(IV)-treated were filtered as differentially expressed compared to the untreated control. Nine of the 17 were downregulated, and the remainder of 8 were upregulated. A complete list of differential gene expression analysis result is included in the supplementary data.

The 3 most over-expressed genes in HA-Pt(IV)-treated were GALTN21, Rps13-ps2, and Nnt; and the 3 most under-expressed genes in the HA-Pt(IV)-treated were EGF, Rps16-ps2, and Dpp10. The highly expressed GALTN21 gene encodes an enzyme, $\mathrm{N}-$

acetylgalactosaminyltransferase 2-like that belongs to a family of over 20 polypeptides of $\mathrm{N}$ acetylgalactosaminyltransferases. This group of transferases catalyzes the transfer of $\mathrm{N}$ acetylgalactosamine from uridine diphosphate $\mathrm{N}$-acetylglucosamine to the hydroxyl group of a serine or threonine residue ${ }^{59}$. The overexpression of GALTN2 has been linked to the inhibition of neuroblastoma proliferation ${ }^{60}$, whereas the underexpression of this gene has been associated with the proliferation, invasion and tumor metastasis of gastric adenocarcinoma $^{61}$. In the current study, the upregulation of GALTN21 in HA-Pt(IV)-treated tumors may partially contribute to the superior tumor suppression and the resultant, improved anti-cancer effectiveness. On the other hand, the underexpressed EGF gene encodes epidermal growth factor protein, which stimulates cell proliferation by binding to the epidermal growth factor receptor. Overexpression of EGF has been correlated with progression and invasiveness of breast cancer ${ }^{62}$. In this analysis, the EGF expression shows significant downregulation in HA-Pt(IV)-treated tumors compared to the untreated control. The underexpression of EGF may explain the prolonged survival and the enhanced tumor suppression observed in the drug treated HNCs compared to the untreated tumors.

Kyoto Encyclopedia of Genes and Genomes (KEGG) and Gene Ontology (GO) enrichment analysis are two of the common downstream procedures to interpret the differential gene expression results in a biological context. GO enrichment analysis effectively categorizes differential gene expressions into specific biological processes. KEGG uses molecular-level information generated from large-scale, high-throughput gene datasets to help elucidate high-level functions and utilities of the biological system ${ }^{63}$.

In the GO analysis, the 3 most significantly enriched GO categories for the HA-Pt(IV) treatment group are: 1) nucleoside diphosphate kinase activity, 2) piRNA metabolic process, and 3) intrinsic component of nuclear inner membrane, which belong to the categories of molecular function-kinase activity, biological process-RNA metabolic process, and cellular component-nuclear membrane, respectively. The 3 most significantly enriched GO categories for the untreated group are: 1) positive regulation of interleukin 12 production, 2) cargo receptor activity, and 3) toxin metabolic process, which belong to the categories of 
biological process-cytokine production, molecular function-cargo receptor activity, and biological process-cellular metabolic process, respectively.

In the KEGG analysis, 89 pathways were enriched and analyzed to understand the biological roles of the differentially expressed genes. In the HA-Pt(IV) treated group, the 5 most important KEGG pathways include: 1) pentose and glucuronate interconversions, 2) starch and sucrose metabolism, 3) ribosome, 4) porphyrin and chlorophyll metabolism, and 5) galactose metabolism (all with $\mathrm{p}<0.037$, and 17 to 83 gene sets). It is worth noting that 4 out of these 5 pathways are associated with metabolism -3 are identified in carbohydrate metabolism; and 1 is identified in cofactor/vitamin metabolism, and 1 of 5 is associated with translation. Of these, carbohydrate metabolism is commonly dysregulated by many types of cancer, and the enrichment of metabolism might be speculated as a sign against cancer. The pathway pattern and the concentration in metabolism are helpful for future mechanism exploration of HA-Pt(IV).

On the other hand, the 5 most important KEGG pathways for the control group include: 1) allograft rejection, 2) leishmania infection, 3) autoimmune thyroid disease, 4) intestinal immune network for IgA production, and 5) primary immunodeficiency (all with $\mathrm{p}<0.033$, and 28 to 62 gene sets). Different from the HA-Pt(IV) treated group, none of the 5 most important pathways involved in the control group are associated with metabolism. Instead, 4 of the 5 most important pathways are associated with immune disease and 1 is associated with infectious disease. The close correlation between the untreated HNCs and the KEGG immune disease pathways may suggest that $\mathrm{HNC}$ is not a localized disease and the immune system may be highly involved in its progression. Therefore, non-traditional therapies such as ICD-eliciting molecules (e.g. HA-Pt(IV)), immunomodulators (e.g. TLR agonists) ${ }^{64,65}$, and immune checkpoint inhibitors (e.g. anti-PD1 antibodies) ${ }^{64,66}$ may be more targeted, effective solutions for treating HNCs compared to conventional therapies that do not activate the immune system.

\section{Conclusion}

In an effort to understand the indications and limitations of evolving platinum chemotherapy, we reported the synthesis, characterization and preclinical testing of a platinum(IV)-based, ICD-eliciting, and carrier-delivered nanoconjugate for potential oncology applications. This study showed for the first time that intralesional Pt(IV) induced a form of ICD in head and neck cancers. In addition, immunological evaluation of the tumors demonstrated increased lymphocyte and macrophage infiltration compared to the intravenous cisplatin treatment. HA-Pt(IV) may also find utility in concurrent chem-oradiation therapy, making practical and effective use of the radiation-sensitizing platinum and the immune responsive radiotherapy. We are currently conducting a clinical study combining intralesional HA-Pt(IV) and radiation therapy in pet dogs with naturally-occurring, externally-accessible malignant tumors at the Kansas State University Veterinary Health Center. Although platinum drugs were discovered over a century ago and have been used in oncology for more than four decades, platinum therapies still offer new interesting avenues for improved treatments. 


\section{Supplementary Material}

Refer to Web version on PubMed Central for supplementary material.

\section{Acknowledgements}

Partial financial support was provided by HylaPharm LLC. RL and LF were partially supported by the National Cancer Institute R01-CA173292 and generous gifts from the Brandmeyer family and Hodgdon family foundations. The KU Genome Sequencing Core and KU NMR labs were supported by NIH grants P20GM103638 and P50GM069663, respectively.

\section{Reference}

1. Vigneswaran N; Williams MD Epidemiologic trends in head and neck cancer and aids in diagnosis. Oral Maxillofac Surg Clin North Am 2014, 26, (2), 123-41. [PubMed: 24794262]

2. https://www.cancer.gov/types/head-and-neck/head-neck-fact-sheet. National Cancer Institute, Accessed on April 11, 2019.

3. Fessas P; Lee H; Ikemizu S; Janowitz T A molecular and preclinical comparison of the PD-1targeted T-cell checkpoint inhibitors nivolumab and pembrolizumab. Semin Oncol 2017, 44, (2), 136-140. [PubMed: 28923212]

4. Cai S; Xie Y; Bagby TR; Cohen MS; Forrest ML Intralymphatic chemotherapy using a hyaluronancisplatin conjugate. J Surg Res 2008, 147, (2), 247-52. [PubMed: 18498877]

5. Cai S; Xie Y; Davies NM; Cohen MS; Forrest ML Pharmacokinetics and disposition of a localized lymphatic polymeric hyaluronan conjugate of cisplatin in rodents. J Pharm Sci 2010, 99, (6), 2664 71. [PubMed: 19960530]

6. Xie Y; Aillon KL; Cai S; Christian JM; Davies NM; Berkland CJ; Forrest ML Pulmonary delivery of cisplatin-hyaluronan conjugates via endotracheal instillation for the treatment of lung cancer. Int J Pharm 2010, 392, (1-2), 156-63. [PubMed: 20363303]

7. Zhang T; Yang Q; Forrest WC; Cai S; Aires D; Forrest ML A Lanthanum-Tagged Chemotherapeutic Agent HA-Pt to Track the In Vivo Distribution of Hyaluronic Acid Complexes. BAOJ Pharm Sci 2015, 1, (1).

8. Zhang T; Cai S; Groer C; Forrest WC; Yang Q; Mohr E; Douglas J; Aires D; Axiak-Bechtel SM; Selting KA; Swarz JA; Tate DJ; Bryan JN; Forrest ML Hyaluronan-Lysine Cisplatin Drug Carrier for Treatment of Localized Cancers: Pharmacokinetics, Tolerability, and Efficacy in Rodents and Canines. J Pharm Sci 2016, 105, (6), 1891-1900. [PubMed: 27155765]

9. Ishiguro S; Cai S; Uppalapati D; Turner K; Zhang T; Forrest WC; Forrest ML; Tamura M Intratracheal Administration of Hyaluronan-Cisplatin Conjugate Nanoparticles Significantly Attenuates Lung Cancer Growth in Mice. Pharm Res 2016, 33, (10), 2517-29. [PubMed: 27335023]

10. Venable RO; Worley DR; Gustafson DL; Hansen RJ; Ehrhart EJ 3rd; Cai S; Cohen MS; Forrest ML Effects of intratumoral administration of a hyaluronan-cisplatin nanoconjugate to five dogs with soft tissue sarcomas. Am J Vet Res 2012, 73, (12), 1969-76. [PubMed: 23176425]

11. Cai S; Xie Y; Davies NM; Cohen MS; Forrest ML Carrier-based intralymphatic cisplatin chemotherapy for the treatment of metastatic squamous cell carcinoma of the head \& neck. Ther Deliv 2010, 1, (2), 237-45. [PubMed: 21339844]

12. Yang Q; Cui H; Cai S; Yang X; Forrest ML In vivo photoacoustic imaging of chemotherapyinduced apoptosis in squamous cell carcinoma using a near-infrared caspase-9 probe. J Biomed Opt 2011, 16, (11), 116026. [PubMed: 22112131]

13. Cohen SM; Rockefeller N; Mukerji R; Durham D; Forrest ML; Cai S; Cohen MS; Shnayder Y Efficacy and toxicity of peritumoral delivery of nanoconjugated cisplatin in an in vivo murine model of head and neck squamous cell carcinoma. JAMA Otolaryngol Head Neck Surg 2013, 139, (4), 382-7. [PubMed: 23599074]

14. Cai S; Zhang T; Forrest WC; Yang Q; Groer C; Mohr E; Aires DJ; Axiak-Bechtel SM; Flesner BK; Henry CJ; Selting KA; Tate D; Swarz JA; Bryan JN; Forrest ML Phase I-II clinical trial of 
hyaluronan-cisplatin nanoconjugate in dogs with naturally occurring malignant tumors. Am J Vet Res 2016, 77, (9), 1005-16. [PubMed: 27580113]

15. Cai S; Zhang T; Groer C; Forrest M; Aires D; Otte V; Barchman S; Faerber A; Forrest ML Injectable Chemotherapy Downstaged Oral Squamous Cell Carcinoma from Nonresectable to Resectable in a Rescue Dog: Diagnosis, Treatment, and Outcome. Case Rep Vet Med 2018, 2018, 9078537. [PubMed: 30402324]

16. Zhang JZ; Bonnitcha P; Wexselblatt E; Klein AV; Najajreh Y; Gibson D; Hambley TW Facile preparation of mono-, di- and mixed-carboxylato platinum(IV) complexes for versatile anticancer prodrug design. Chemistry 2013, 19, (5), 1672-6. [PubMed: 23255183]

17. Wexselblatt E; Yavin E; Gibson D Platinum(IV) prodrugs with haloacetato ligands in the axial positions can undergo hydrolysis under biologically relevant conditions. Angew Chem Int Ed Engl 2013, 52, (23), 6059-62. [PubMed: 23686723]

18. Galanski M; Keppler BK Synthesis and Characterization of New Ethylenediamine Platinum(IV) Complexes Containing Lipophilic Carboxylate Ligands. Met Based Drugs 1995, 2, (1), 57-63. [PubMed: 18472746]

19. Ma J; Wang Q; Yang X; Hao W; Huang Z; Zhang J; Wang X; Wang PG Glycosylated platinum(iv) prodrugs demonstrated significant therapeutic efficacy in cancer cells and minimized side-effects. Dalton Trans 2016, 45, (29), 11830-8. [PubMed: 27373800]

20. Theiner S; Grabarics M; Galvez L; Varbanov HP; Sommerfeld NS; Galanski M; Keppler BK; Koellensperger $\mathrm{G}$ The impact of whole human blood on the kinetic inertness of platinum(iv) prodrugs - an HPLC-ICP-MS study. Dalton Trans 2018, 47, (15), 5252-5258. [PubMed: 29560976]

21. Hall MD; Amjadi S; Zhang M; Beale PJ; Hambley TW The mechanism of action of platinum(IV) complexes in ovarian cancer cell lines. J Inorg Biochem 2004, 98, (10), 1614-24. [PubMed: 15458824]

22. Chen CK; Zhang JZ; Aitken JB; Hambley TW Influence of equatorial and axial carboxylato ligands on the kinetic inertness of platinum(IV) complexes in the presence of ascorbate and cysteine and within DLD-1 cancer cells. J Med Chem 2013, 56, (21), 8757-64. [PubMed: 24107138]

23. Sabbatini M; Zanellato I; Ravera M; Gabano E; Perin E; Rangone B; Osella D Pt(IV) Bifunctional Prodrug Containing 2-(2-Propynyl)octanoato Axial Ligand: Induction of Immunogenic Cell Death on Colon Cancer. J Med Chem 2019, 62, (7), 3395-3406. [PubMed: 30879295]

24. Hato SV; Khong A; de Vries IJ; Lesterhuis WJ Molecular pathways: the immunogenic effects of platinum-based chemotherapeutics. Clin Cancer Res 2014, 20, (11), 2831-7. [PubMed: 24879823]

25. Kroemer G; Galluzzi L; Kepp O; Zitvogel L Immunogenic cell death in cancer therapy. Annu Rev Immunol 2013, 31, 51-72. [PubMed: 23157435]

26. Tesniere A; Schlemmer F; Boige V; Kepp O; Martins I; Ghiringhelli F; Aymeric L; Michaud M; Apetoh L; Barault L; Mendiboure J; Pignon JP; Jooste V; van Endert P; Ducreux M; Zitvogel L; Piard F; Kroemer G Immunogenic death of colon cancer cells treated with oxaliplatin. Oncogene 2010, 29, (4), 482-91. [PubMed: 19881547]

27. Suntharalingam K; Song Y; Lippard SJ Conjugation of vitamin E analog alpha-TOS to Pt(IV) complexes for dual-targeting anticancer therapy. Chem Commun (Camb) 2014, 50, (19), 2465-8. [PubMed: 24452361]

28. Zhang T; Cai S; Forrest WC; Mohr E; Yang Q; Forrest ML Development and Validation of an Inductively Coupled Plasma Mass Spectrometry (ICP-MS) Method for Quantitative Analysis of Platinum in Plasma, Urine, and Tissues. Appl Spectrosc 2016, 70, (9), 1529-36. [PubMed: 27527103]

29. Hier MP; Black MJ; Shenouda G; Sadeghi N; Karp SE A murine model for the immunotherapy of head and neck squamous cell carcinoma. Laryngoscope 1995, 105, (10), 1077-80. [PubMed: 7564839]

30. Paolini F; Massa S; Manni I; Franconi R; Venuti A Immunotherapy in new preclinical models of HPV-associated oral cancers. Hum Vaccin Immunother 2013, 9, (3), 534-43. [PubMed: 23296123] 
31. Golden EB; Frances D; Pellicciotta I; Demaria S; Helen Barcellos-Hoff M; Formenti SC Radiation fosters dose-dependent and chemotherapy-induced immunogenic cell death. Oncoimmunology 2014, 3, e28518. [PubMed: 25071979]

32. Tomayko MM; Reynolds CP Determination of subcutaneous tumor size in athymic (nude) mice. Cancer Chemother Pharmacol 1989, 24, (3), 148-54. [PubMed: 2544306]

33. Andrews S FastQC: A Quality Control Tool for High Throughput Sequence Data. http:// www.bioinformatics.babraham.ac.uk/projects/fastqc/ (5/14/2020),

34. Patro R; Duggal G; Love MI; Irizarry RA; Kingsford C Salmon provides fast and bias-aware quantification of transcript expression. Nature Methods 2017, 14, (4), 417-419. [PubMed: 28263959]

35. Genome Reference Consortium Mouse Build 38. https://www.ncbi.nlm.nih.gov/assembly/ GCF_000001635.20/ (5/14/2020),

36. Soneson C; Love MI; Robinson MD Differential analyses for RNA-seq: transcript-level estimates improve gene-level inferences. F1000Research 2015, 4, 1521. [PubMed: 26925227]

37. Subramanian A; Tamayo P; Mootha VK; Mukherjee S; Ebert BL; Gillette MA; Paulovich A; Pomeroy SL; Golub TR; Lander ES; Mesirov JP Gene set enrichment analysis: a knowledge-based approach for interpreting genome-wide expression profiles. Proc Natl Acad Sci U S A 2005, 102, (43), 15545-50. [PubMed: 16199517]

38. Mootha VK; Lindgren CM; Eriksson KF; Subramanian A; Sihag S; Lehar J; Puigserver P; Carlsson E; Ridderstrale M; Laurila E; Houstis N; Daly MJ; Patterson N; Mesirov JP; Golub TR; Tamayo P; Spiegelman B; Lander ES; Hirschhorn JN; Altshuler D; Groop LC PGC-1alpharesponsive genes involved in oxidative phosphorylation are coordinately downregulated in human diabetes. Nat Genet 2003, 34, (3), 267-73. [PubMed: 12808457]

39. Zhang JZ; Wexselblatt E; Hambley TW; Gibson D Pt(IV) analogs of oxaliplatin that do not follow the expected correlation between electrochemical reduction potential and rate of reduction by ascorbate. Chem Commun (Camb) 2012, 48, (6), 847-9. [PubMed: 22124352]

40. Zheng YR; Suntharalingam K; Johnstone TC; Yoo H; Lin W; Brooks JG; Lippard SJ Pt(IV) prodrugs designed to bind non-covalently to human serum albumin for drug delivery. J Am Chem Soc 2014, 136, (24), 8790-8. [PubMed: 24902769]

41. He S; Cong Y; Zhou D; Li J; Xie Z; Chen X; Jing X; Huang Y A dextranplatinum(IV) conjugate as a reduction-responsive carrier for triggered drug release. J. Mater. Chem. B 2015, 3, 8203-8211. [PubMed: 32262878]

42. Ling X; Shen Y; Sun R; Zhang M; Li C; Mao J; Xing J; Sun C; Tu J Tumor-targeting delivery of hyaluronic acid-platinum(IV) nanoconjugate to reduce toxicity and improve survival. Polym Chem 2015, 6, 1541-1552.

43. Carr JL; Tingle MD; McKeage MJ Rapid biotransformation of satraplatin by human red blood cells in vitro. Cancer Chemother Pharmacol 2002, 50, (1), 9-15. [PubMed: 12111106]

44. Sternberg CN; Petrylak DP; Sartor O; Witjes JA; Demkow T; Ferrero JM; Eymard JC; Falcon S; Calabro F; James N; Bodrogi I; Harper P; Wirth M; Berry W; Petrone ME; McKearn TJ; Noursalehi M; George M; Rozencweig M Multinational, double-blind, phase III study of prednisone and either satraplatin or placebo in patients with castrate-refractory prostate cancer progressing after prior chemotherapy: the SPARC trial. J Clin Oncol 2009, 27, (32), 5431-8. [PubMed: 19805692]

45. Cohen SM; Mukerji R; Cai S; Damjanov I; Forrest ML; Cohen MS Subcutaneous delivery of nanoconjugated doxorubicin and cisplatin for locally advanced breast cancer demonstrates improved efficacy and decreased toxicity at lower doses than standard systemic combination therapy in vivo. Am J Surg 2011, 202, (6), 646-52; discussion 652-3. [PubMed: 21982998]

46. Yang Q; Aires DJ; Cai S; Fraga GR; Zhang D; Li CZ; Forrest ML In vivo efficacy of nano hyaluronan-conjugated cisplatin for treatment of murine melanoma. J Drugs Dermatol 2014, 13, (3), 283-7. [PubMed: 24595572]

47. Cohen MS; Cai S; Xie Y; Forrest ML A novel intralymphatic nanocarrier delivery system for cisplatin therapy in breast cancer with improved tumor efficacy and lower systemic toxicity in vivo. Am J Surg 2009, 198, (6), 781-6. [PubMed: 19969129] 
48. Bagby TR; Cai S; Duan S; Thati S; Aires DJ; Forrest L Impact of molecular weight on lymphatic drainage of a biopolymer-based imaging agent. Pharmaceutics 2012, 4, (2), 276-95. [PubMed: 24300232]

49. Lovgren T; Sarhan D; Truxova I; Choudhary B; Maas R; Melief J; Nystrom M; Edback U; Vermeij R; Scurti G; Nishimura M; Masucci G; Karlsson-Parra A; Lundqvist A; Adamson L; Kiessling R Enhanced stimulation of human tumor-specific $\mathrm{T}$ cells by dendritic cells matured in the presence of interferon-gamma and multiple toll-like receptor agonists. Cancer Immunol Immunother 2017, 66, (10), 1333-1344. [PubMed: 28601925]

50. Casares N; Pequignot MO; Tesniere A; Ghiringhelli F; Roux S; Chaput N; Schmitt E; Hamai A; Hervas-Stubbs S; Obeid M; Coutant F; Metivier D; Pichard E; Aucouturier P; Pierron G; Garrido C; Zitvogel L; Kroemer G Caspase-dependent immunogenicity of doxorubicin-induced tumor cell death. J Exp Med 2005, 202, (12), 1691-701. [PubMed: 16365148]

51. Pfirschke C; Engblom C; Rickelt S; Cortez-Retamozo V; Garris C; Pucci F; Yamazaki T; PoirierColame V; Newton A; Redouane Y; Lin YJ; Wojtkiewicz G; Iwamoto Y; Mino-Kenudson M; Huynh TG; Hynes RO; Freeman GJ; Kroemer G; Zitvogel L; Weissleder R; Pittet MJ Immunogenic Chemotherapy Sensitizes Tumors to Checkpoint Blockade Therapy. Immunity 2016, 44, (2), 343-54. [PubMed: 26872698]

52. Kepp O; Senovilla L; Vitale I; Vacchelli E; Adjemian S; Agostinis P; Apetoh L; Aranda F; Barnaba V; Bloy N; Bracci L; Breckpot K; Brough D; Buque A; Castro MG; Cirone M; Colombo MI; Cremer I; Demaria S; Dini L; Eliopoulos AG; Faggioni A; Formenti SC; Fucikova J; Gabriele L; Gaipl US; Galon J; Garg A; Ghiringhelli F; Giese NA; Guo ZS; Hemminki A; Herrmann M; Hodge JW; Holdenrieder S; Honeychurch J; Hu HM; Huang X; Illidge TM; Kono K; Korbelik M; Krysko DV; Loi S; Lowenstein PR; Lugli E; Ma Y; Madeo F; Manfredi AA; Martins I; Mavilio D; Menger L; Merendino N; Michaud M; Mignot G; Mossman KL; Multhoff G; Oehler R; Palombo F; Panaretakis T; Pol J; Proietti E; Ricci JE; Riganti C; Rovere-Querini P; Rubartelli A; Sistigu A; Smyth MJ; Sonnemann J; Spisek R; Stagg J; Sukkurwala AQ; Tartour E; Thorburn A; Thorne SH; Vandenabeele P; Velotti F; Workenhe ST; Yang H; Zong WX; Zitvogel L; Kroemer G; Galluzzi L Consensus guidelines for the detection of immunogenic cell death. Oncoimmunology 2014, 3, (9), e955691. [PubMed: 25941621]

53. Martins I; Kepp O; Schlemmer F; Adjemian S; Tailler M; Shen S; Michaud M; Menger L; Gdoura A; Tajeddine N; Tesniere A; Zitvogel L; Kroemer G Restoration of the immunogenicity of cisplatin-induced cancer cell death by endoplasmic reticulum stress. Oncogene 2011, 30, (10), 1147-58. [PubMed: 21151176]

54. Hughes R; Qian BZ; Rowan C; Muthana M; Keklikoglou I; Olson OC; Tazzyman S; Danson S; Addison C; Clemons M; Gonzalez-Angulo AM; Joyce JA; De Palma M; Pollard JW; Lewis CE Perivascular M2 Macrophages Stimulate Tumor Relapse after Chemotherapy. Cancer Res 2015, 75, (17), 3479-91. [PubMed: 26269531]

55. DeNardo DG; Brennan DJ; Rexhepaj E; Ruffell B; Shiao SL; Madden SF; Gallagher WM; Wadhwani N; Keil SD; Junaid SA; Rugo HS; Hwang ES; Jirstrom K; West BL; Coussens LM Leukocyte complexity predicts breast cancer survival and functionally regulates response to chemotherapy. Cancer Discov 2011, 1, (1), 54-67. [PubMed: 22039576]

56. Chen L; Li J; Wang F; Dai C; Wu F; Liu X; Li T; Glauben R; Zhang Y; Nie G; He Y; Qin Z Tie2 Expression on Macrophages Is Required for Blood Vessel Reconstruction and Tumor Relapse after Chemotherapy. Cancer Res 2016, 76, (23), 6828-6838. [PubMed: 27758887]

57. Zhao Y; Zhang C; Gao L; Yu X; Lai J; Lu D; Bao R; Wang Y; Jia B; Wang F; Liu Z Chemotherapy-Induced Macrophage Infiltration into Tumors Enhances Nanographene-Based Photodynamic Therapy. Cancer Res 2017, 77, (21), 6021-6032. [PubMed: 28916656]

58. Panni RZ; Linehan DC; DeNardo DG Targeting tumor-infiltrating macrophages to combat cancer. Immunotherapy 2013, 5, (10), 1075-87. [PubMed: 24088077]

59. Hussain MR; Hoessli DC; Fang M N-acetylgalactosaminyltransferases in cancer. Oncotarget 2016, 7, (33), 54067-54081. [PubMed: 27322213]

60. Ho WL; Chou CH; Jeng YM; Lu MY; Yang YL; Jou ST; Lin DT; Chang HH; Lin KH; Hsu WM; Huang MC GALNT2 suppresses malignant phenotypes through IGF-1 receptor and predicts favorable prognosis in neuroblastoma. Oncotarget 2014, 5, (23), 12247-59. [PubMed: 25362349] 
61. Liu SY; Shun CT; Hung KY; Juan HF; Hsu CL; Huang MC; Lai IR Mucin glycosylating enzyme GALNT2 suppresses malignancy in gastric adenocarcinoma by reducing MET phosphorylation. Oncotarget 2016, 7, (10), 11251-62. [PubMed: 26848976]

62. Khazaie K; Schirrmacher V; Lichtner RB EGF receptor in neoplasia and metastasis. Cancer Metastasis Rev 1993, 12, (3-4), 255-74. [PubMed: 8281612]

63. KEGG analysis. https://www.genome.jp/kegg/, Accessed on May 6, 2020.

64. Sato-Kaneko F; Yao S; Ahmadi A; Zhang SS; Hosoya T; Kaneda MM; Varner JA; Pu M; Messer KS; Guiducci C; Coffman RL; Kitaura K; Matsutani T; Suzuki R; Carson DA; Hayashi T; Cohen EE Combination immunotherapy with TLR agonists and checkpoint inhibitors suppresses head and neck cancer. JCI Insight 2017, 2, (18).

65. Wittig B; Schmidt M; Scheithauer W; Schmoll HJ MGN1703, an immunomodulator and toll-like receptor 9 (TLR-9) agonist: from bench to bedside. Crit Rev Oncol Hematol 2015, 94, (1), 31-44. [PubMed: 25577571]

66. Mandal R; Senbabaoglu Y; Desrichard A; Havel JJ; Dalin MG; Riaz N; Lee KW; Ganly I; Hakimi AA; Chan TA; Morris LG The head and neck cancer immune landscape and its immunotherapeutic implications. JCI Insight 2016, 1, (17), e89829. [PubMed: 27777979] 

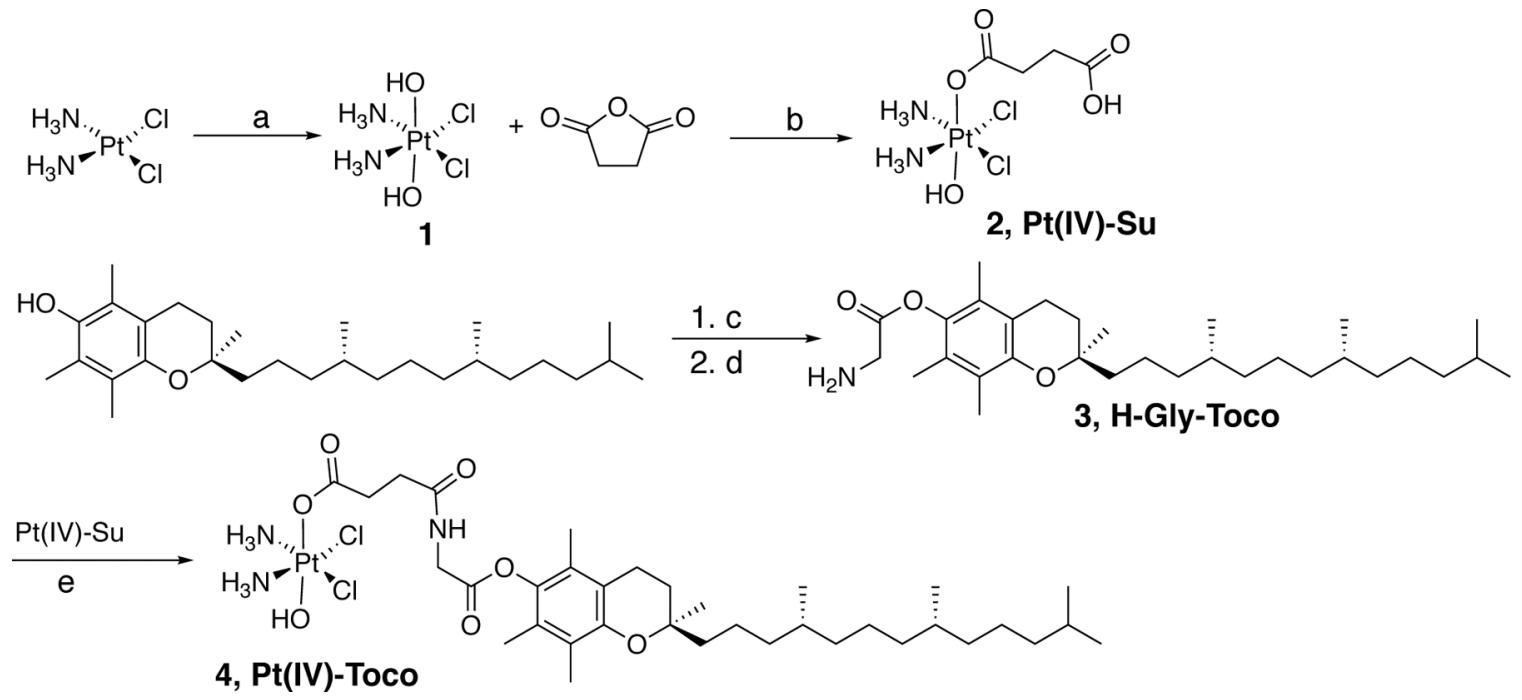

Figure 1.

Synthetic scheme of Pt(IV)-Tocopherol [Pt(IV)-Toco] conjugate. a, water, $\mathrm{H}_{2} \mathrm{O}_{2}, 50{ }^{\circ} \mathrm{C}$; b, DMSO, $25^{\circ} \mathrm{C}$; c, Boc-Gly-OH, DCC, DMAP, DCM; d, TFA, DCM; and e, HATU, DIPEA, DMSO. 

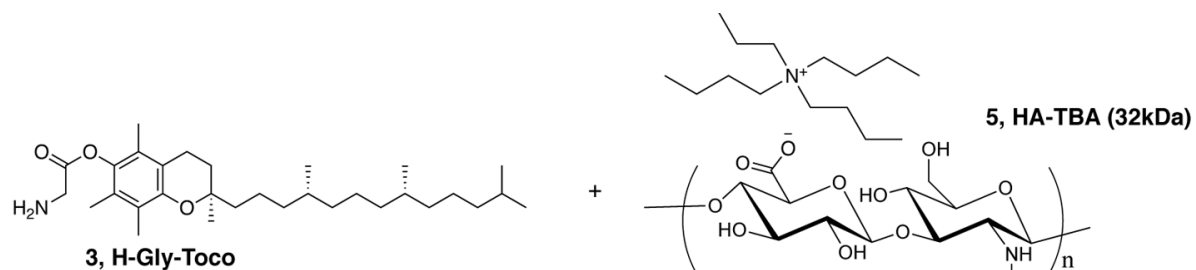

3, H-Gly-Toco
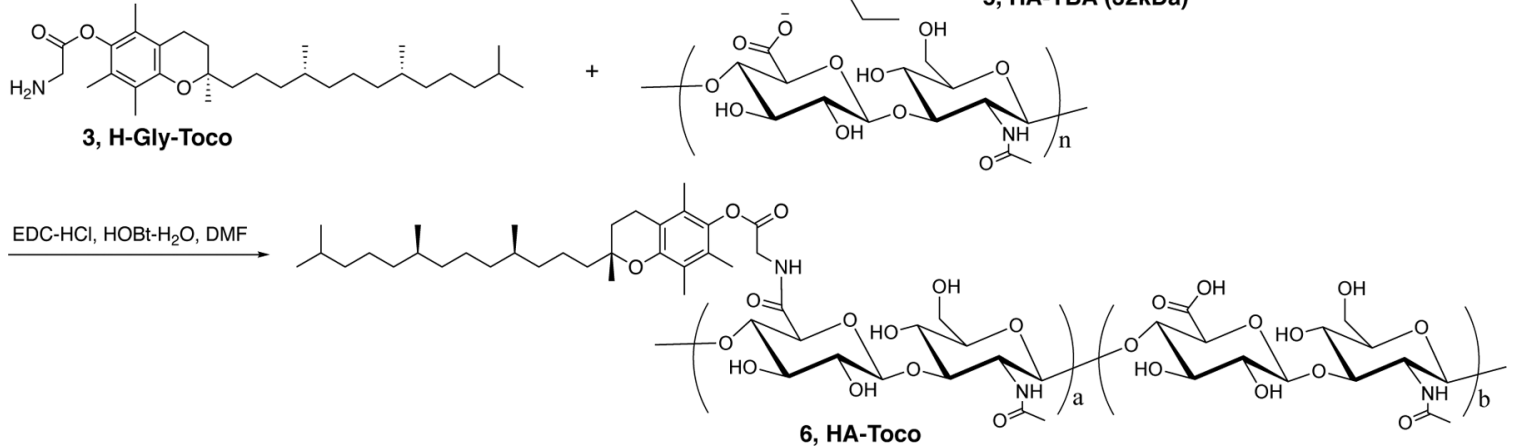

Figure 2.

Synthetic scheme of HA-Toco. 


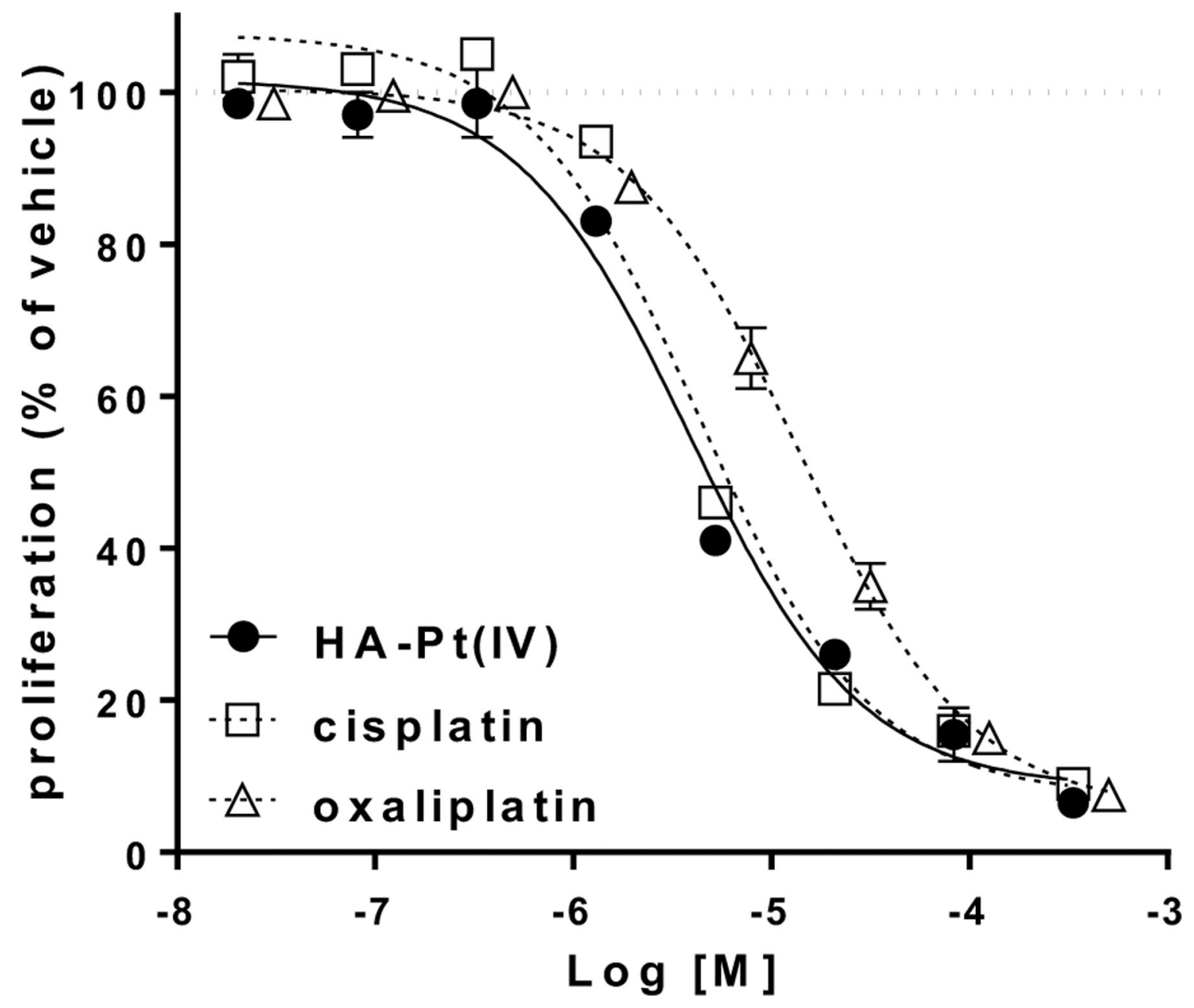

Figure 3.

HA-Pt(IV) inhibits growth of head and neck cancer cells. AT84 cells were cultured in the presence of increasing concentrations of compounds for 72 hours and cell proliferation was quantified. Data from at least five separate experiments was analyzed by non-linear regression. Representative dose response curves are shown. All drugs show full efficacy. Potencies are HA-Pt(IV) $\mathrm{IC}_{50}=6.1 \pm 1.1 \mu \mathrm{M}$, cisplatin $\mathrm{IC}_{50}=3.0 \pm 0.3 \mu \mathrm{M}$, and oxaliplatin $\mathrm{IC}_{50}=13.6 \pm 3.8 \mu \mathrm{M}(\mathrm{n}=7-8)$. 


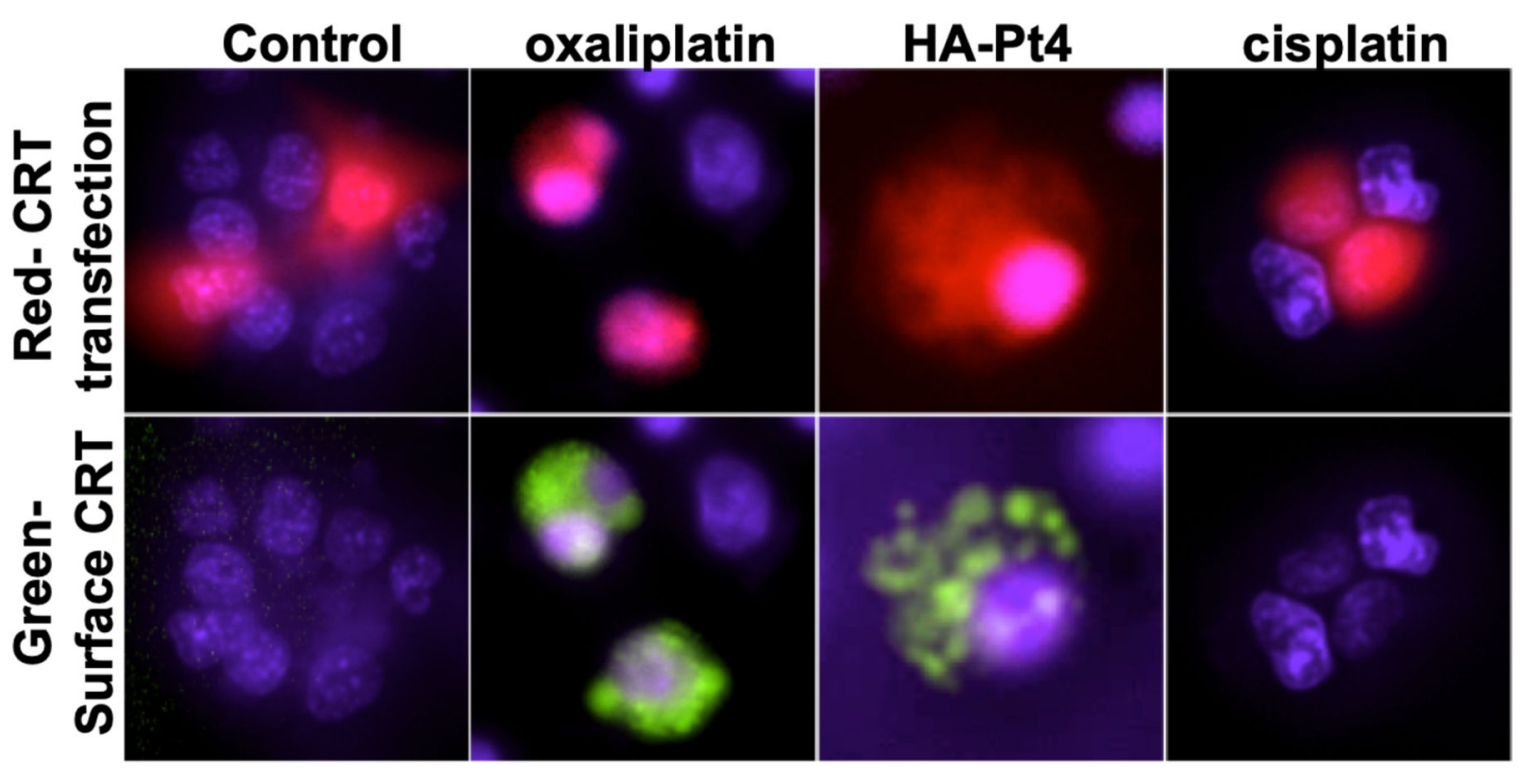

Figure 4.

HA-Pt(IV) causes calreticulin translocation to the cell surface. AT84 cells were transfected with mouse CRT-HaloTag ${ }^{\circledR}$-KDEL fusion protein. Positively transfected cells are identified by the CayenneRFP reporter protein expressed from the same plasmid (red, top panel). After incubation with drug (500uM; 15 hours), membrane translocation of CRT-HaloTag® is visualized by addition of the membrane impermeable HaloTag ${ }^{\circledR}$ Ligand Alexa Fluor $^{\circledR} 488$ (green, bottom panel). The positive control oxaliplatin and HA-Pt(IV) show CRT translocation, indicating ICD. In contrast, cisplatin does not show CRT translocation, consistent with a lack of ICD induction. Live cells were imaged using a 60x objective. Representative images are shown from 3 independent experiments. 
$\checkmark$ AT84, vehicle -ఈ- MDA1986, vehicle

$\rightarrow$ AT84, HA-Pt(IV) $\rightarrow-$ MDA1986, HA-Pt(IV)

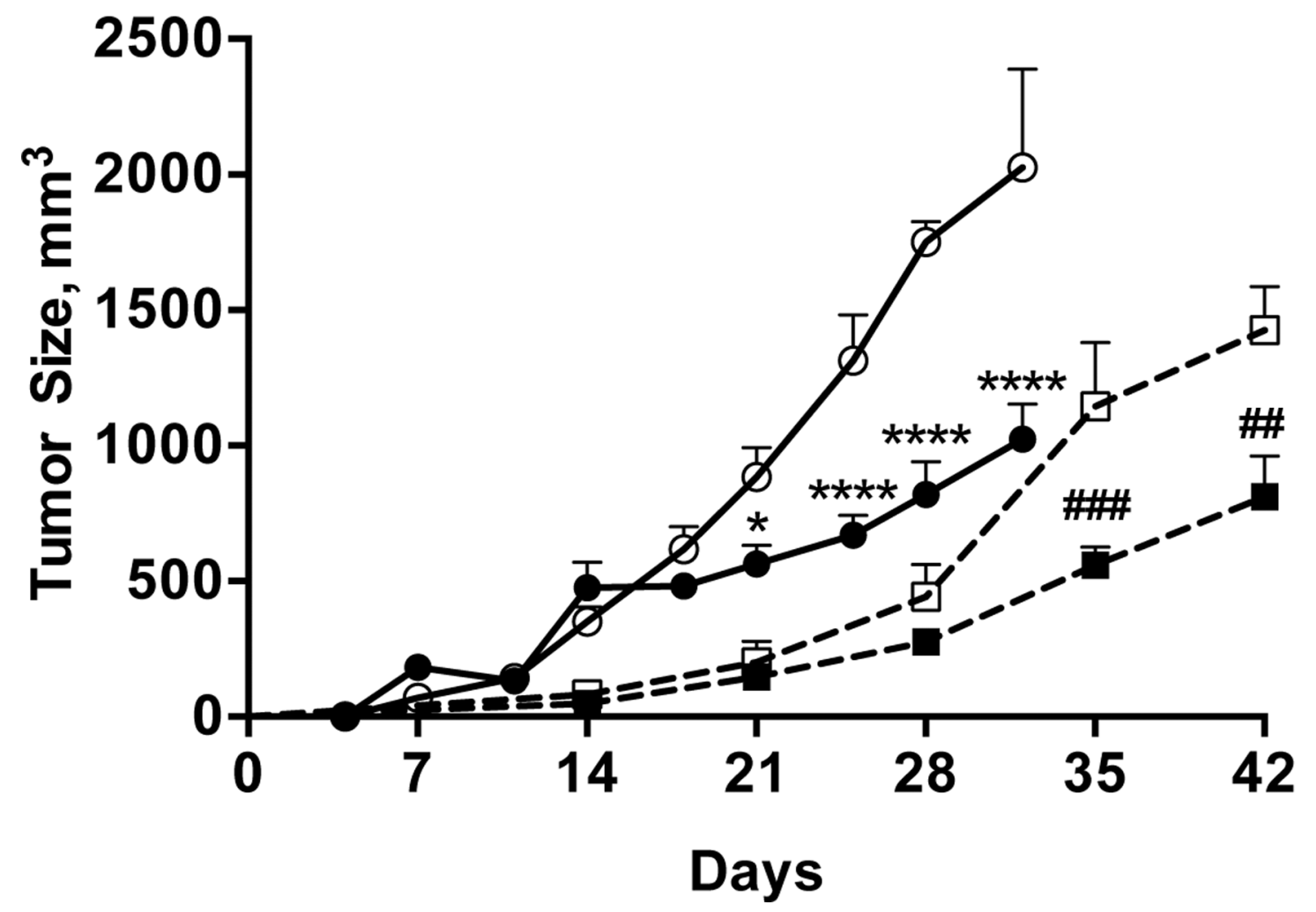

Figure 5.

HA-Pt(IV) demonstrated growth inhibition of head and neck tumors in immunocompetent (AT84) and immunodeficient (MDA1986) mouse models (mean \pm SEM). HA-Pt(IV) treatment significantly reduced AT84 tumor growth compared to vehicle controls in immuno-competent $\mathrm{C} 3 \mathrm{H}$ mice (two-way ANOVA, $\mathrm{p}<0.0001$ for treatment, time, and interaction; Sidak's multiple comparisons test, $\left.{ }^{*} \mathrm{p}<0.05,{ }^{*} * * * \mathrm{p}<0.0001 ; \mathrm{n}=6-8\right)$. In the immuno-compromised MDA1986 model, HA-Pt(IV) treatment also significantly reduced tumor growth (two-way ANOVA, $\mathrm{p}<0.001$ for treatment, $\mathrm{p}<0.0001$ time, and $\mathrm{p}<0.01$ interaction; Sidak's multiple comparisons test, \#\#p<0.01,\#\#\#< <0.001; n=8). Individual growth curves are included in the supplementary data. 

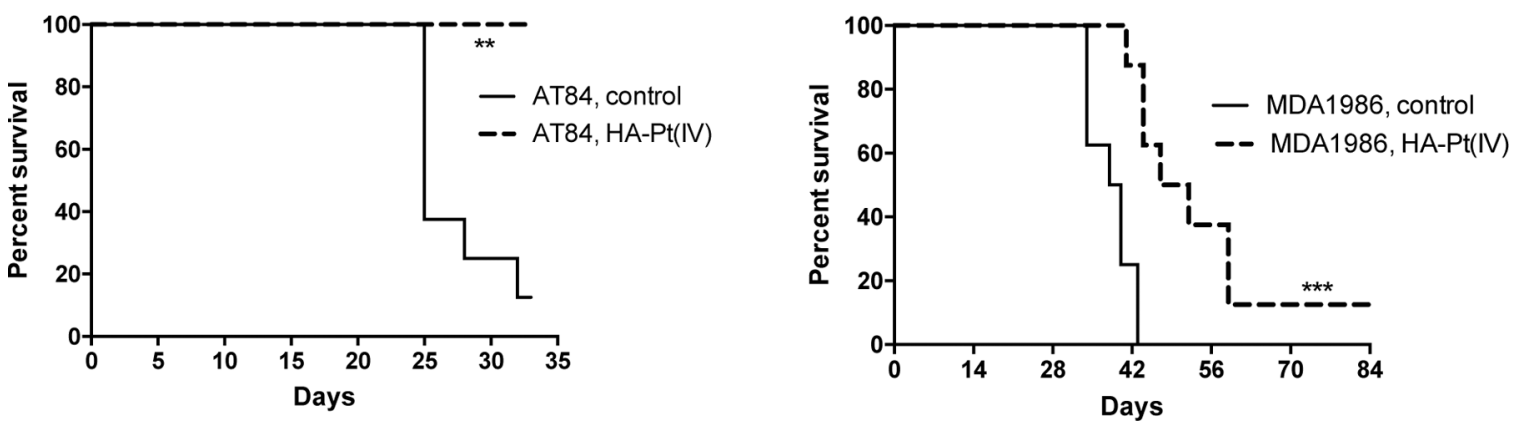

Figure 6.

Survival rates of MDA-1986 and AT84 tumor models. The control and the HA-Pt(IV) treated groups differed significantly in both models (Mantel-Cox, $* * \mathrm{p}<0.01, * * * \mathrm{p}<0.001$; $n=6-8)$. 


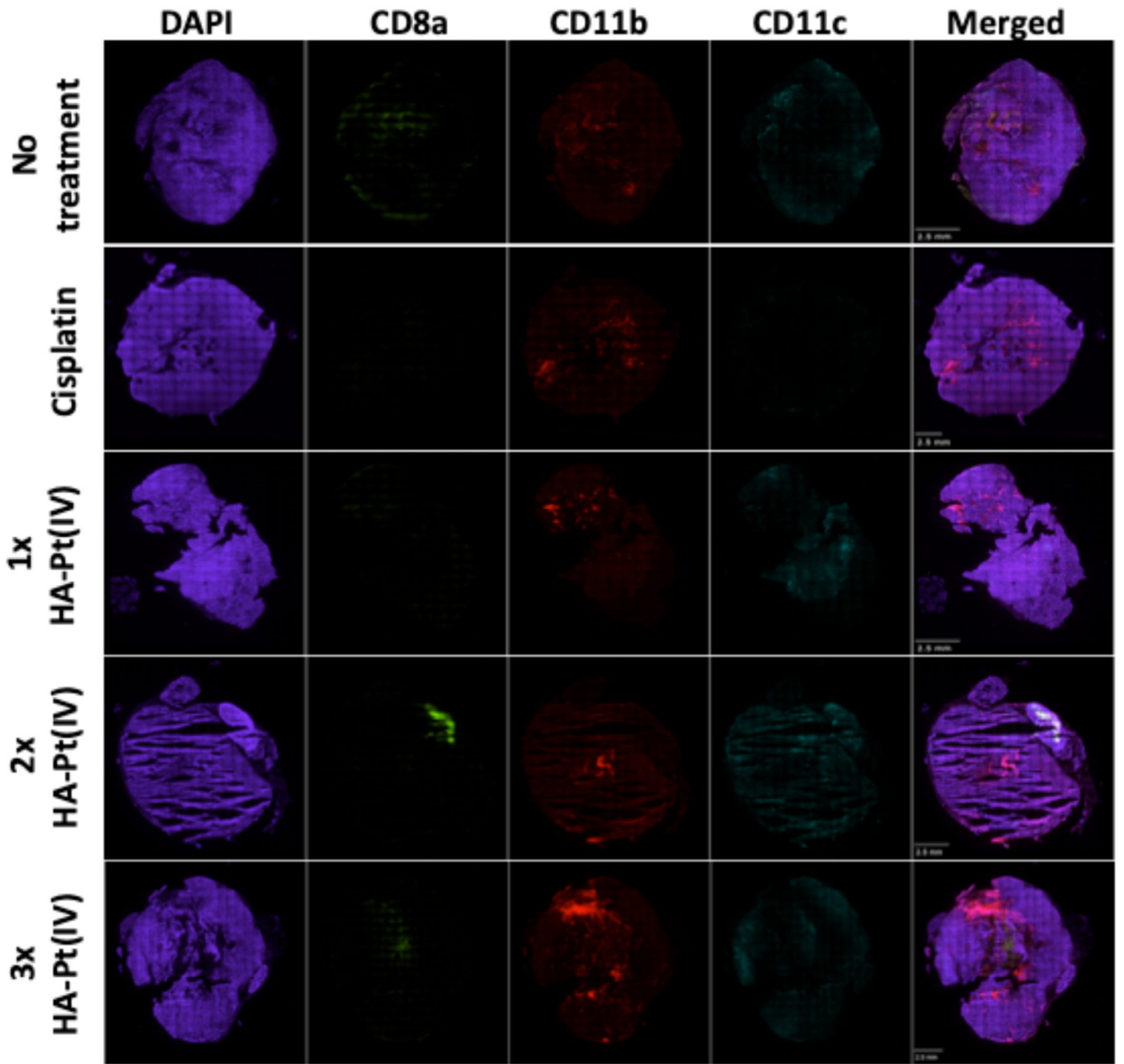

Figure 7.

Mouse AT84 tumors treated with either intravenous cisplatin or intratumoral HA-Pt(IV), and stained with DAPI, CD8a, CD11b and CD11c. 


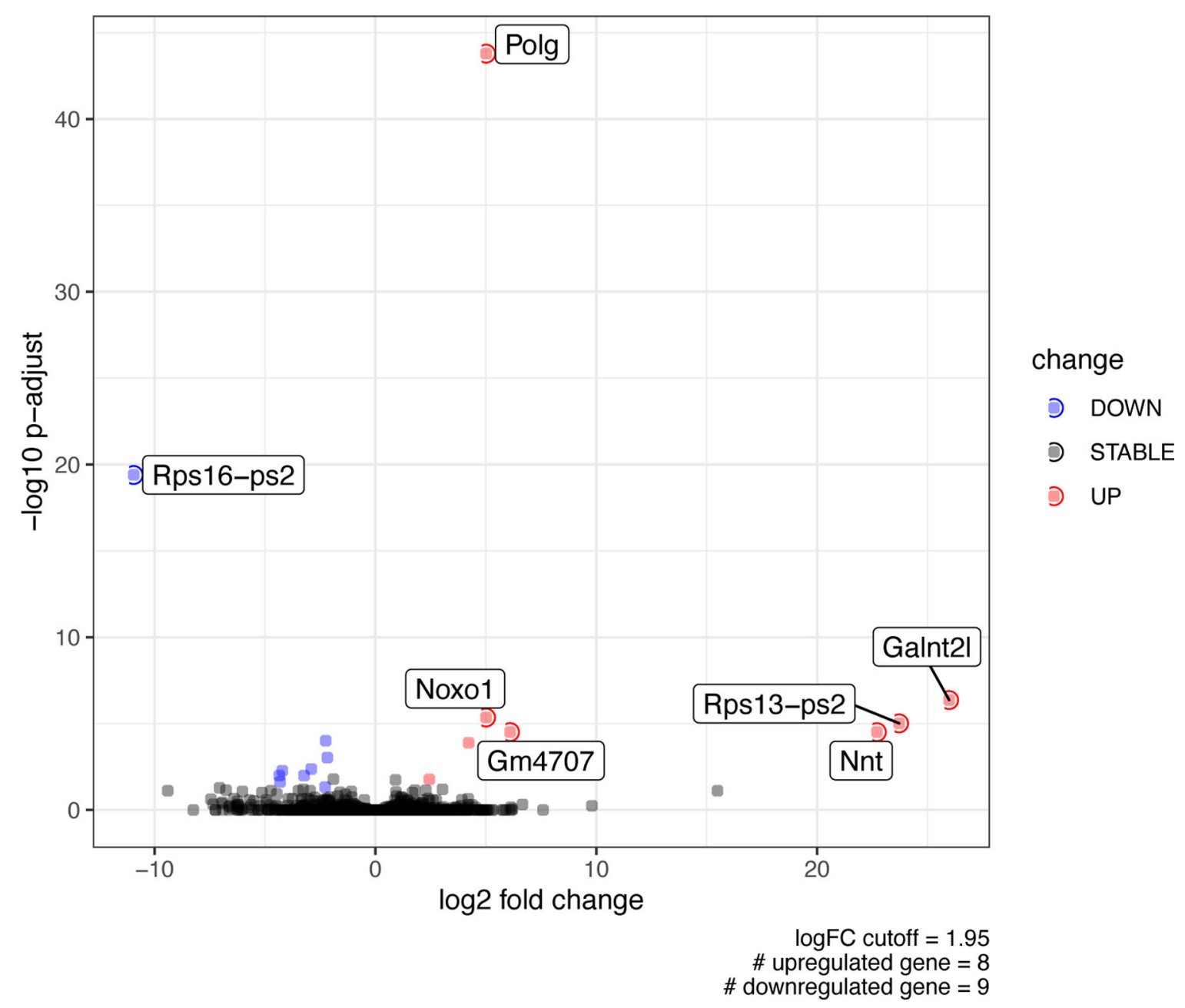

Figure 8.

Volcano plot of the gene expression analysis. 